\title{
Nanosized microporous crystals: emerging applications
}

Svetlana Mintova, ${ }^{1, *}$ Maguy Jaber, ${ }^{2,3}$ Valentin Valtchev ${ }^{1}$

${ }^{1}$ Laboratoire Catalyse \& Spectrochimie, ENSICAEN - Université de Caen - CNRS

6, boulevard Maréchal Juin, 14050 Caen, France

${ }^{2}$ UPMC Paris 06, UMR 8220, Laboratoire d'archéologie moléculaire et structurale, LAMS, F-75005, 4 place Jussieu, BP225, Paris, France

${ }^{3}$ CNRS, UMR 8220, LAMS, F-75005, Paris, France

\begin{abstract}
This review highlights recent developments in the synthesis and unconventional applications of nanosized microporous crystals including namely framework (zeolites) and layered (clays) type materials. Owing to their micropore nature nanosized zeolites and clays exhibit novel properties, different from those of bulk materials. The factors controlling the formation of nanosized microporous crystals are first revised. The most promising approaches from the viewpoint of large-scale production of nanosized zeolites and clays are discussed in depth. The preparation and advanced applications of nanosized zeolites and clays in free (suspension and powder forms) and fixed (films) forms are summarized. Further the review is accentuated on the new, non-conventional for porous materials, applications. A comprehensive analysis of the emerging applications of microporous nanosized crystals in the fields of semiconductor industry, optical materials, chemical sensors, medicine, cosmetics, and food industry is presented. Finally, the future needs and perspectives for nanosized microporous materials (zeolites and clays) are addressed.
\end{abstract}

\section{Introduction}

Zeolites and clays are minerals with widespread occurrence in various Earth's crust environments and with great impact in different areas of the chemical process industries and nanotechnology. ${ }^{1}$ Both zeolites and clays crystallize in water-rich and low pressure environment under wide range of temperature. ${ }^{2,3}$ Under such conditions low-density watercontaining structures are formed. The major difference between these two groups of minerals is the type of the structure formed, which in the case of clays is two dimensional (2D) while 
the zeolites exhibit a three dimensional framework (3D). Both clays and zeolite contain exchangeable cations and water molecules in the intra-crystalline space. In the case of clay minerals cation-water complexes are situated between sheets built of $\mathrm{SiO}_{4}$ and other cations. While, three-dimensional zeolite frameworks contain well define pores and cavities able to discriminate species with different sizes less than $1 \AA$. The zeolite frameworks are fairly rigid and exhibit limited flexibility. Zeolites exhibit shape selectivity of molecules of dimension similar with their channels. Depending on the pore opening the zeolites are subdivided of small, medium and large pore channels, as the later are able to process molecules with size between 7 and $8 \AA$. Extra large pore (> $8 \AA$ ) zeolites were also obtained, however, because of limited framework stability and difficulties in tuning framework composition they are not used for practical applications. In contrast, the inter-lamellar space of clays can be expanded substantially and thus they could adsorb molecules larger than zeolites. The zeolites and clays exhibit complementarity in their properties, which are summarized in Figure 1. They are utilized as natural as well as synthetic materials but for demanding advanced technological applications predominantly synthetic zeolites and clays are used with carefully engineered properties obtained by controlled crystal growth.

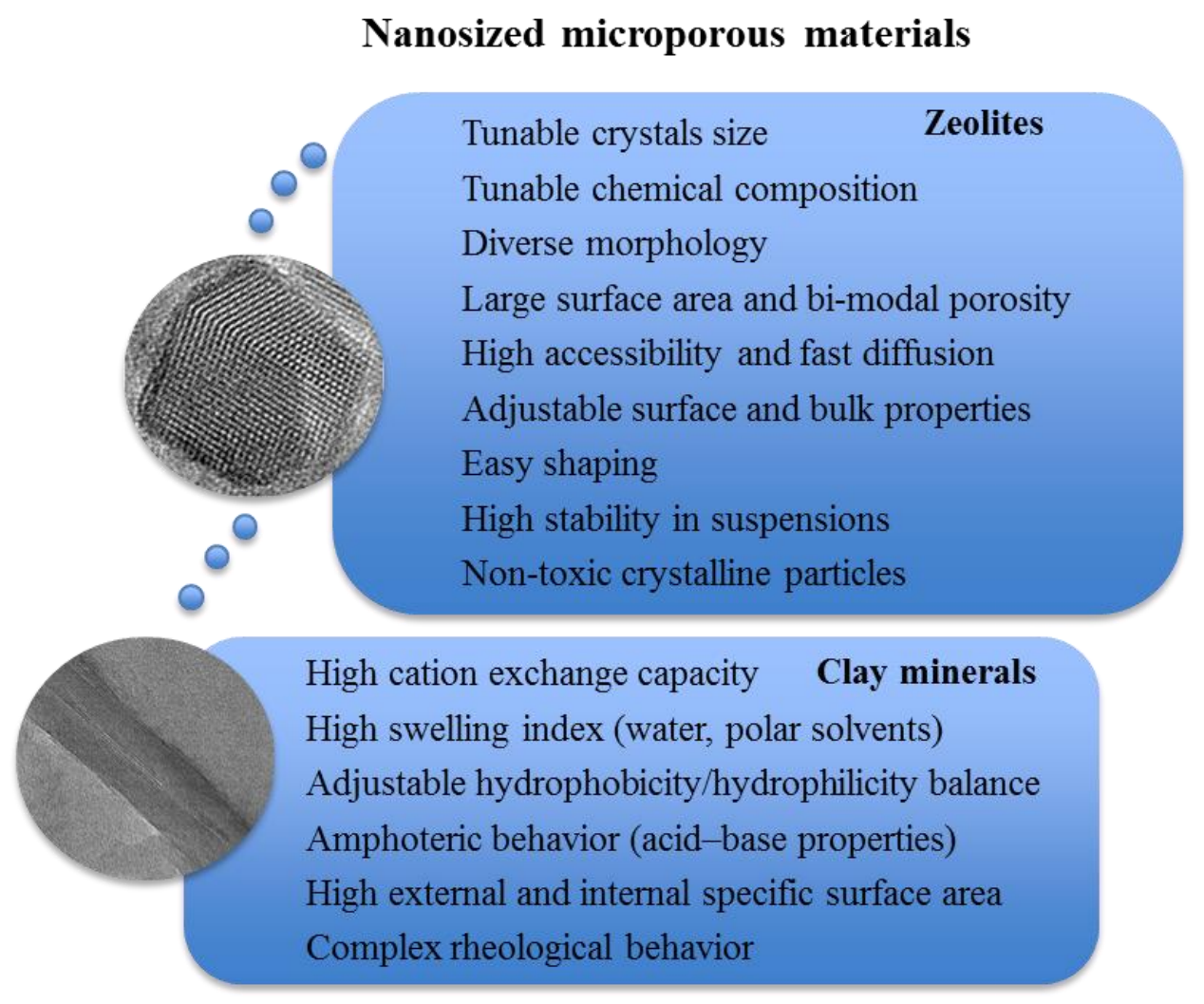

Figure 1. Most important properties and differences of nanosized microporous materials: (a) zeolites and (b) clays. 
Zeolites and clays are widely used in chemical process industry as heterogeneous catalysts, adsorbents and ion exchangers. Their importance is enormous for such key areas as petroleum refining, petrochemicals and fine chemicals production, separation of toxic and radioactive wastes, air pollution abatement, industrial effluent and water purification. The use of clays and zeolites ranges from heavy chemical processes and environmental protection, to household needs and lately to advanced applications. The wide use of these materials is due to their particular structures and related properties, such as accessible intracrystalline volume and thus much larger specific surface area in respect to dense materials. The presence of channels with molecular dimension and active sites that can be tuned make these materials excellent heterogeneous catalysts and molecular sieves. Although porous with high specific surface area and accessible crystalline volume, the size of zeolites and clays is important for their performance.

Separation and catalytic transformation of different species (ions, molecules) are based on surface reaction with atoms situated at the surface of a sold material. Thus the number, nature and distribution of the active centres of materials are of paramount importance for their efficiency in diverse processes. The available surface for bulk materials depends on the particles' size. Hence, the only option to increase the available surface is to decrease the size (Figure 2a) and thus to increase the portion of the atoms that are able to get in contact with foreign species. Additionally, the microporous materials offer the advantage that the major part of atoms is accessible via the intracrystalline channels (Figure 2b). Nevertheless, the size of microporous materials is also important since it determines the diffusion path thorough micropore space. By combining the small size with creation of micropores in the crystals, substantial change of their properties is expected (Figure 2c). Very often the microporous materials suffer from diffusion limitation and pore blocking by bulky molecules, which substantially reduces the performance of the material. Thus, one of most attractive property of micronsized microporous materials, the shape selectivity, could become a serious drawback and substantially deteriorate their performance in a catalytic or a separation reaction. A straightforward solution is the decrease of microporous crystals size that could substantially limit the impact of diffusion limitations. Thus, the preparation of nanosized crystals is important to improve the performance of microporous materials in a number of processes.

The nanosized crystals (zeolites and clays) are defined as materials with dimensions in the range 5 - $500 \mathrm{~nm}$; materials with particle dimension in the range $500-1000 \mathrm{~nm}$ belong to the class of "nanosized" materials, however their properties are similar to the micronsized 
counterparts. A substantial increase of the fraction of the atoms on zeolite/clay surface could also be used to perform reactions with very bulky molecules that cannot defuse in micropore space. Finally, nanosized zeolite crystals and clays are important for a number of emerging applications related with the development of advanced materials.

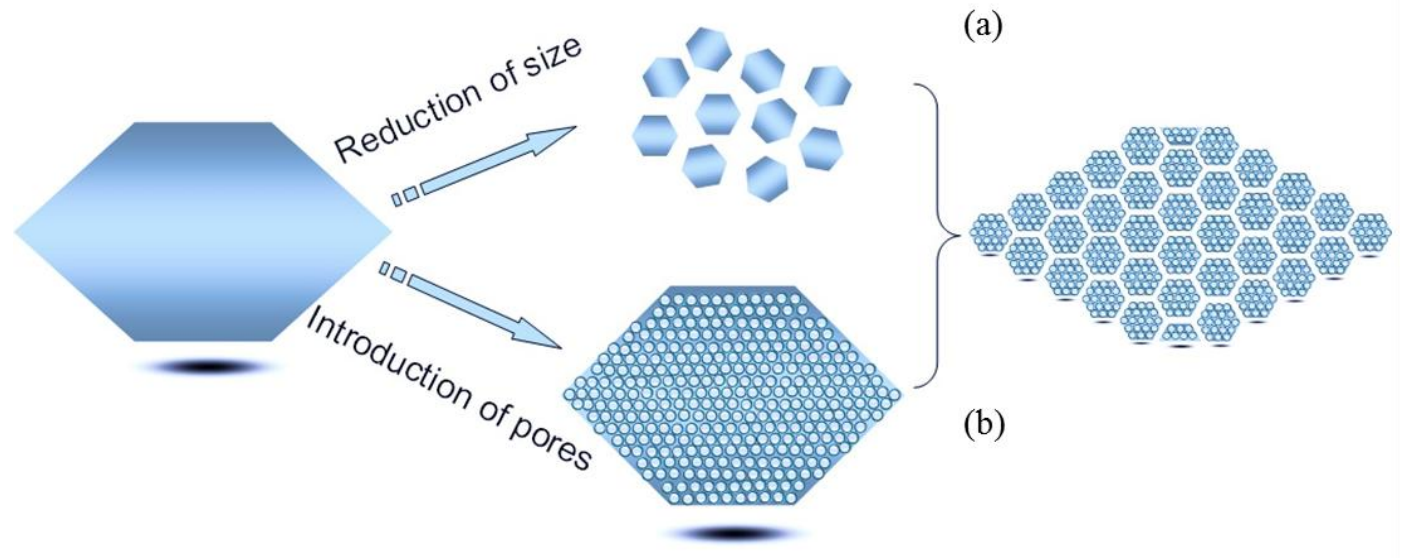

Figure 2. Available surface area of crystals increased by (a) decreasing the size of particles, (b) introduction of pores, and by combining both (c) decrease of size and introduction of pores in nanosized crystals.

There are already a number of papers that review the synthesis, modification and applications of nanosized porous particles. ${ }^{4-6}$ The aim of present article is to overview latest development in the field paying special attention to the emerging uses of microporous crystals. We have limited our study to classical silica-based microporous crystals since the major part of the new advanced applications are based on such materials.

Nanostructured materials are classified according to the number of dimensions at the nanometer range. We will reveal the properties of nanoparticles in all three dimensions as (a) zeolites and (b) clays with diverse structures with prospect applications in nanotechnology (Figure 3). Both the zeolite and clays are porous materials, however the zeolites have framework type structures with 1-, 2- or 3-dimensional pores, while clays are layered materials with 1-dimensional pores. There is growing interest in the preparation of nanosized microporous materials due to the different physicochemical properties in comparison to their micronsized counterparts. At the nanometer dimension, materials exhibit novel properties, different to those of both the isolated atom and bulk (above micron-sized dimensions) materials. Also it is important to differentiate between 'free' and 'fixed' nanoparticles that can be considered for different applications. The nanoparticles can be designed intentionally via 
"synthesis engineering" or the nanoparticles can be prepared by post-synthesis treatments. In this review, the emphasis will be on in situ prepared nanosized microporous materials.

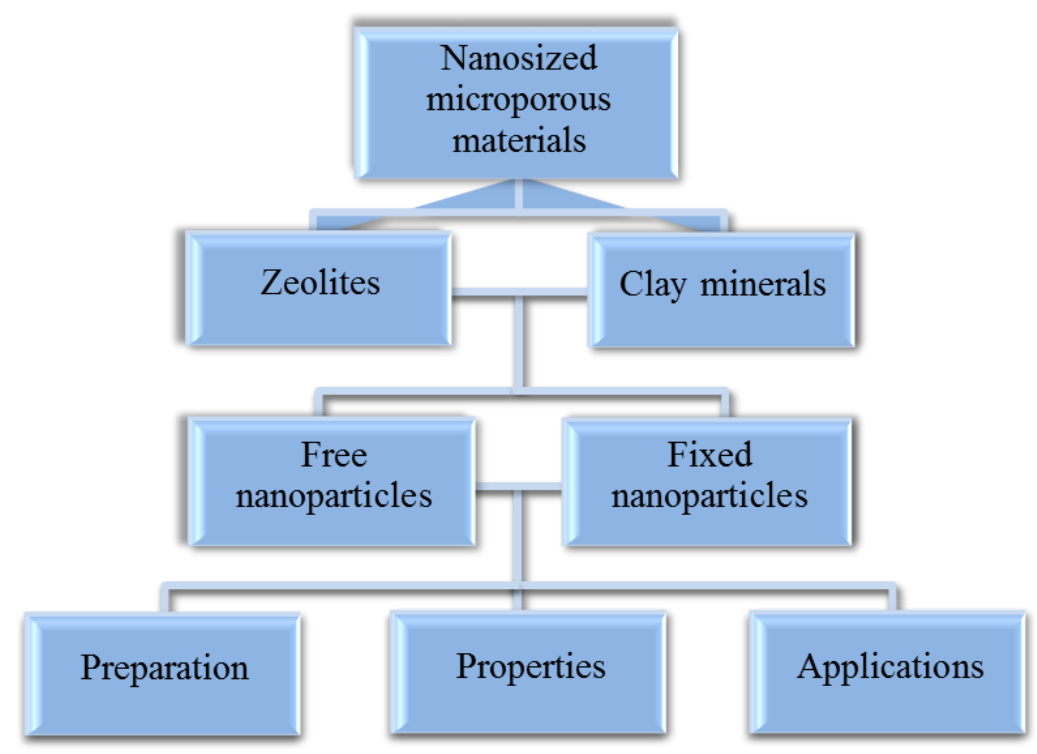

Figure 3. Key issues of nanosized microporous materials: zeolites and clays.

\section{Nanosized zeolites}

Zeolite nucleation is a spontaneous process leading to the formation of viable nuclei that grow into crystals. ${ }^{7,8}$ The zeolite yielding systems are fairly different in terms of chemistry and physical appearance of the precursor. They can vary from water clear suspensions to dry powders containing only traces of water. The common feature of laboratory syntheses is that the crystallization is performed in close systems and very rarely fresh reactants are added in the course of zeolite crystallization. Synthesis under such conditions allows control of the ultimate crystal size via the nucleation process. More precisely, the number of the viable nuclei in the system determines the ultimate crystal size since after the conversion of the amorphous precursors into crystals the growth process stops. Hence, the systems with abundant nucleation yield small crystallites, whereas the ones that generate a few nuclei provide relatively large ones. It has to be underlined, however, that the size of the crystallites can be small $(5-500 \mathrm{~nm})$ but they might form large intergrown agglomerates (above $1 \mu \mathrm{m}$ ). Often the performance of such agglomerates is similar to micron-sized crystals. Therefore, in order to take advantage of small crystal size, single not agglomerated nanocrystals are highly desired. 
In general, the synthesis of zeolites is performed from a hydrogel. These systems exhibit distinct solid (gel) and liquid (mother liquor) part and they are highly non-uniform. Usually the products from such systems are zeolite crystals with size of about one micron, the intergrowth and the agglomeration from one system to another differ and this is highly dependent of the initial reactants used, the alkali and water contents. Briefly the process of zeolite nucleation and growth in hydrogel system is highly unpredictable and far from well controlled.

\subsection{Non-conventional synthesis of nanosized zeolites}

The difficulties in the control of the crystals size in conventional zeolite-yielding systems resulted in the development of alternative methods of synthesis. Such an approach that circumvents the difficulties in the control of zeolite nucleation is the confined space synthesis. In this case the ultimate crystal size is determined by the available free space, which is limited by some physical or chemical barrier. The first example of such synthesis was published by Madsen and Jacobsen. ${ }^{9}$ They synthesized zeolites in the voids of porous carbon particles and removed the carbon by combustion to obtain nanosized zeolite crystals. Later on, the hard carbon templates were replaced by organic matrixes, such as $\operatorname{strach}^{10}$ and polymer hydrogels. $^{11}$

Besides hard and soft templates were also used to control the growth of zeolite crystals. Serrano and co-workers have demonstrated that ZSM-5 growth can be controlled by surface functionalization of growing crystals. ${ }^{12,13}$ Different types of silanes containing amino, mercapto and allyl surface groups were used. In all cases the synthesized crystals were smaller than those synthesized from the same initial system without using silanes. It should be mentioned that beside the size, the presence of silanes changed the Si/Al ratio and the surface charge of the nanosized zeolites.

Jo et al. reported the use of multivalent surfactants for restricting the growth of zeolite crystals and thus the formation of nanosized particles. ${ }^{14}$ The effect of surfactant on the zeolite crystals size is attributed to the multiply binding of surfactant's functional groups to zeolite surface, which limits the growth. Zeolites with MOR, FAU, CHA and MFI framework topology where synthesized. In any case, however, the zeolite nanocrystals were heavily aggregated. Similar approach was used by Jamil et al., who employed a polyoxyethilene-based surfactant to control the size and the crystal aspect ratio of TON-type zeolite. ${ }^{15}$ A decrease of the crystal length from 300 to $90 \mathrm{~nm}$ was observed. Microwave (MW) radiation was used in this 
synthesis. Again MW heating, but employing a water-in-oil microemulsion was used to synthesize FAU type zeolite nanocrystals. ${ }^{16}$ Small water droplets were used as microreactors to limit the zeolite growth. The size of synthesized FAU type crystals (zeolite X) varied between 10 and $30 \mathrm{~nm}$. Conventional heating yielded crystals with size of about $150 \mathrm{~nm}$.

MW heating offers the advantage of rapid and uniform heating in the reaction vessel, ${ }^{17}$ usually the result is more homogeneous and abundant nucleation in the system. Thus, different types of microporous materials were synthesized in the form of nanocrystrals. ${ }^{5}$ It should be mentioned that the method is more efficient in the synthesis of aluminophosphate than aluminosilicate microporous materials. For instance, MW irradiation was used to initiate the nucleation of SAPO-34 and then the system was subjected to conventional hydrothermal treatment at $200{ }^{\circ} \mathrm{C}$ for $24 \mathrm{~h} .{ }^{18}$ The authors reported a pronounced effect of the MW power on the nucleation process. The nucleation initiated at higher MW power $(210 \mathrm{~W})$ is more abundant, but the crystals tend to aggregate, whereas the use of lower (140 W) power yields less but non-aggregated nuclei.

Similarly to MW heating the sonification provides smaller crystals than the conventional synthesis. ${ }^{19}$ Recently nanosized zeolite NaP was synthesized by sonochemical of the initial gel followed by conventional hydrothermal treatment. ${ }^{20}$ Small about $50 \mathrm{~nm}$ zeolite P crystals were obtained. However, most of the crystals were agglomerated and form large particles. The authors underlined the importance of sonication energy for the formation of active radicals, which promote the rapid zeolite formation.

Dry-gel conversion (DGC) method for preparation of zeolites could also be considered as a non-conventional synthesis approach for nanocrystals. The method is based on the preliminary preparation of an initial zeolite yielding gel, which is dried and then subjected to crystallization in vapour phase. In such ultra-dense gel usually the nucleation process is abundant. However, closely situated nucleuses usually formed aggregates. Yue et al. employed the DGC process to prepare shaped ZSM-5 agglomerates. ${ }^{21}$ A particularity in their approach is the use of seeds (MFI-type) that were mixed with aluminoslicate precursor and extruded to shape columned bodies. The synthesis was performed in vapour phase at $175^{\circ} \mathrm{C}$ for different periods of time. Besides water, the vapour phase contained $\mathrm{NH}_{4} \mathrm{OH}$, ethylamine or butylamine. The best results were obtained with ethylamine, which combines high alkalinity with high-saturated vapour pressure. Depending on the synthesis conditions, zeolite particles with size between 200 and $800 \mathrm{~nm}$ were synthesized. The reference experiment without addition of the seeds yielded relatively large ZSM-5 crystals. Zeolite bodies exhibited significant mechanical strength. 


\subsection{Conventional synthesis of nanosized zeolites}

The synthesis of a zeolite from a hydrogel precursor in a close reactor upon conventional heating is considered as "conventional synthesis". First synthesis of nanosized zeolite was reported by Meng et al. ${ }^{22}$ Nanosized zeolite L crystals with uniform particle size of 50-100 $\mathrm{nm}$ building larger agglomerates were obtained.

First syntheses of nanosized single zeolite crystals that do not agglomerate were reported in the early 90 s by Schoeman et al. ${ }^{23-25}$ The syntheses of ZSM-2, FAU-, LTA- and SOD-type zeolites were described in these studies. After purification zeolite nanocrystals were stabilized in the form of colloidal suspensions with narrow particle size distribution. The systems yielding such uniform nanocrystals were called "clear solutions". In fact, the initial systems used were optically clear suspensions containing discrete colloidal particles. Although not completely homogeneous these systems provide the necessary condition for a uniform nucleation and crystal growth. Consequently the obtained nanocrystals are uniform in size and the agglomeration of the particles is limited.

The stabilization of a suspension containing discrete zeolite particles requires specific conditions in each stage of their preparation. First the employed reactants and the conditions have to be properly selected. Further, the alkali metal content has to be as low as possible in order to avoid the aggregation between the particles. The absence of alkali cations is compensated with abundant amounts of tetraalkylammonium hydroxides (TAAOH) that keep the basicity of the system high and act as structure directing agents (SDAs). The homogenisation of the reactants is gentle to avoid the aggregation of precursor particles. Thus a suspension containing uniform in size particle is stabilized. Usually the system used is very diluted to avoid the aggregation between the growing crystals. Crystallization temperature is typically lower than the one traditionally used for the synthesis of a particular zeolite, which favours the nucleation over the growth. Upon heating the amorphous precursor particles convert into nanosized zeolite. With increase the number and the size of colloidal particles initially optically clear solution turns to turbid and then to milky white. Besides the specific preparation procedure, the nanosized zeolites require a specific post-synthesis treatment in order to avoid severe aggregation between the particles. The excess of organic templates and unreacted silica/alumina are separated by high-speed centrifugation, and redispersion of zeolite nanoparticles in distilled water is usually performed. The procedure is repeated several times and then the $\mathrm{pH}$ of resultant suspension is adjusted to about 9 with diluted $\mathrm{NH}_{4} \mathrm{OH}$. The 
goal of latter procedure is to keep the negative charge of colloidal zeolite crystals high. The repulsive forces of negatively charged particles protect the particles from further aggregation. Freeze drying is used when dry powder of zeolite nanocrystals is needed. This process limits the aggregation between the crystallites. The calcination of organic template-containing zeolite nanocrystals is usually performed under the conditions used for the micron-sized counterpart. The micropore volume of highly crystalline nanosized zeolites is expected to be similar to the micronsized crystals. This is in the case of fully crystalline nanosized zeolites (see Figure 4). As can be anticipated the nanocrystals exhibit substantially higher external surface area.

The use of clear suspension is very efficient process that provides high quality nanosized zeolite particles. However, because of specific conditions used, namely highly diluted systems crystallizing at relatively low temperature, the crystalline yield is much lower than that from a gel-rich initial system. On the other hand, clear precursor suspensions were found very useful in studies devoted to the zeolite crystallization mechanism. The uniformity of the initial system and the simultaneity of the crystallization events make them indispensable for understanding of the zeolite nucleation and growth processes. For instance, the precursor suspension with a chemical composition 9TPAOH:25 $\mathrm{SiO}_{2}: 480 \mathrm{H}_{2} \mathrm{O}$ (TPAOH is tetrapropylammonium hydroxide), first used by Persson et al. to synthesize nanosized silicalite-1 is one of most largely exploited system. ${ }^{26}$ With slight variations of the TPAOH and $\mathrm{H}_{2} \mathrm{O}$ contents, this system was used in tenth of studies devoted to zeolite nucleation and substantial advances in understanding of the nature of colloidal precursors yielding zeolite were achieved. $^{27-33}$

Another "clear" precursor suspension allowed visualizing the "birth" of LTA-type zeolite. ${ }^{34}$ The system used was 13.4 (TMA) $\mathrm{O}_{2}: 0.3 \mathrm{Na}_{2} \mathrm{O}: 1.8 \mathrm{Al}_{2} \mathrm{O}_{3}: 11.25 \mathrm{SiO}_{2}: 700 \mathrm{H}_{2} \mathrm{O}$, where as organic template (TMAOH is tetramethylammonium hydroxide) was used. The crystallization was performed at room temperature for a week. After mixing the initial reactants $40-80 \mathrm{~nm}$ amorphous particles were formed. Each amorphous particle yielded a zeolite crystal. The formation of zeolite nuclei was observed in the centre of each particle and then the crystalline network propagated outward direction till the complete transformation of the amorphous particles into crystalline was reached. It is noteworthy that the size and the morphology of the crystal were similar with the amorphous precursor particles. According to the X-ray diffraction (XRD) and transmission electron microscopy (TEM) study these particle were fully crystalline. Only after heating at elevated temperature larger cubic shape zeolite A crystals were observed. Similar process of formation was observed in the case of FAU-type 
zeolite synthesized from TMAOH-rich initial system. ${ }^{35}$ Again a low Na-content initial solution was used, but the crystallization was performed at elevated temperature. The crystallization mechanism followed at elevated temperature shows that it is not specific for ambient temperature conditions only. The question that arises is whether colloidal precursor particles can be stabilized in a Na-rich initial system and further to be transformed into nanosized zeolite by a similar pathway.

Very recently ultra small EMT-type zeolite, which is the hexagonal counterpart of cubic FAU-type zeolite, was synthesized from an organic template-free Na-rich initial system. ${ }^{36}$ The mechanism of formation was similar to the one observed in the synthesis of LTA- and FAUtype zeolites synthesized from TMAOH-rich colloidal precursors. First amorphous colloidal particles were formed and upon moderate heating $\left(30-40^{\circ} \mathrm{C}\right)$ these particles have gradually transformed into EMT-type zeolite crystals with no substantial changes of their size. The dynamic light scattering (DLS) measurements showed almost the same particles size for the amorphous precursor and crystalline zeolite particles. Ultra small plate-like hexagonal EMTtype crystals were synthesized. The crystal thickness along $a$ and $c$ directions was $13-15 \mathrm{~nm}$ and $4 \mathrm{~nm}$, respectively. These dimensions correspond approximately of $7 \times 2$ unit cells crystallite. Such small single nanocrystals were not synthesized up to this study, including in organic template-containing initial systems. ${ }^{4,6}$ The factors playing key role in this spectacular synthesis were: first the stabilization of colloidal precursor suspension in the presence of large amount of $\mathrm{Na}$, and second the synthesis perform at low temperature $\left(40{ }^{\circ} \mathrm{C}\right)$. It is important to note that in order to avoid an uncontrolled polymerization of the aluminosilicate precursor particles, special precaution was taken to the preparation of initial suspensions and the order of reagents mixing. An aluminate and a silicate solution with similar $\mathrm{NaOH}$ content were prepared and cooled down to $4{ }^{\circ} \mathrm{C}$. The addition of small portion of one solution to another under vigorous stirring ensured the formation of discrete amorphous particles. The hydrothermal treatment under a moderate temperature allowed the conversion of the amorphous precursor into crystalline zeolite without favouring of the Ostwald repining. It is worth nothing that the synthesis at low temperature was important not only to limit the growth of the crystals, but also to avoid the formation of competing phases as LTA-, SOD, GIS- or FAU-type zeolites. ${ }^{37}$ Thus the ultimate crystals were similar in size with the amorphous particles. This synthesis is equally remarkable by the fact that EMT-type zeolite was synthesized solely with sodium as a structure-directing agent. Previously this zeolite was obtained using a 18 -crown-6 ether. ${ }^{38,39}$ The use of this very expensive SDA was the main 
obstacle to industrial use of EMT-type zeolite, which exhibit great potential in catalytic and separation processes.

Recently, organic additives were used to control the formation of EMT type zeolite in a sodium-rich initial system. $^{40}$ Triethanolamine, tetramethylammonium and tetraethylammonium were employed in this study. The triethanolamine had the most pronounced effect on the crystal growth process of the EMT type zeolite providing larger crystals $(100 \mathrm{~nm})$ with framework composition different from the counterpart obtained in an organic-free precursor system. The effect of triethanolamine was attributed to the immobilization of $\mathrm{Al}$ in the initial suspension, and thus partial suppression of zeolite nucleation was observed.

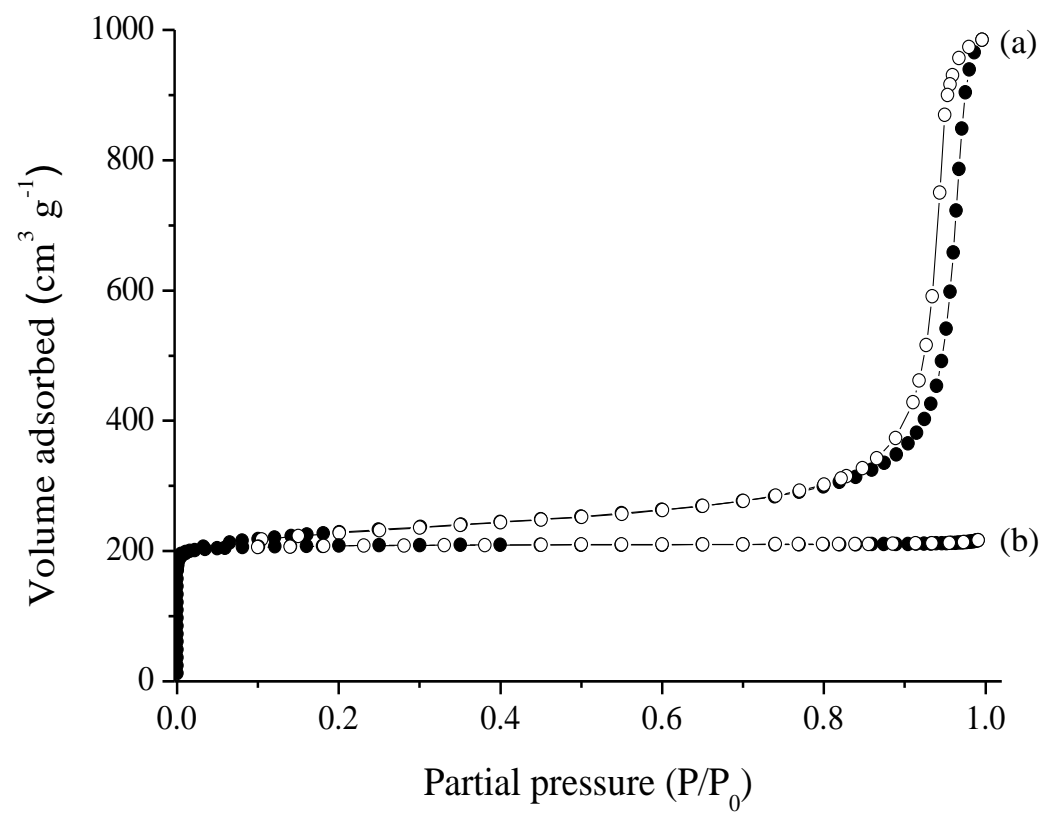

Figure 4. Nitrogen adsorption/desorption isotherms of (a) nanosized (particles of $10 \mathrm{~nm}$ ) and (b) micronsized $(1 \mu \mathrm{m})$ FAU type zeolites.

The strategy employed in the preparation of Na-EMT nanocrystals was further applied in the synthesis of FAU-type zeolite. Again the stabilization of clear suspension of discrete gel particles was amongst the key factors in the synthesis of organic template-free FAU-type nanocrystals. The zeolite was synthesized at low temperature and also at $100{ }^{\circ} \mathrm{C}$, which is common for the synthesis of FAU-type zeolite. Both, zeolite $\mathrm{Y}$ and zeolite $\mathrm{X}$ were obtained by varying the initial precursor composition. It is important to note that the zeolite Y particles with size 10, 70 and $400 \mathrm{~nm}$ were synthesized. ${ }^{41}$ Products with high crystallinity and 
micropore volume equal to micron-sized crystals were obtained (Figure 4). It is remarkable that ultra small zeolite crystals can be synthesized with such high crystallinity and preserved micropore volume. The nanosized FAU zeolite exhibits a mix of Type I and IV isotherms with a large H1 type hysteresis (Figure 4a). Such a feature is associated with textural pores formed by the close packing of monodispersed and well-shaped nanosized crystallites; the total pore volume of this sample is $1.54 \mathrm{~cm}^{3} \mathrm{~g}^{-1}$ while the micron-sized FAU zeolite has 0.35 $\mathrm{cm}^{3} \mathrm{~g}^{-1}$. The results underline the high crystallinity and quality of the nanosized FAU crystals prepared from organic template-free precursor suspension; this is not observed when nanosized FAU crystals are synthesized in the presence of organic agents. ${ }^{35}$ The micropore volume for both the nanosized and micronsized FAU zeolites is equal to $0.31 \mathrm{~cm}^{3} \mathrm{~g}^{-1}$; a value typical of highly crystalline material. Another important feature of the nanosized FAU zeolite is the high external surface area, $270 \mathrm{~m}^{2} \mathrm{~g}^{-1}$, opening opportunities for processes taking place specifically on this part of the zeolite in comparison to $30 \mathrm{~m}^{2} \mathrm{~g}^{-1}$ for the micronsized FAU zeolite. The prospects for this material, both in new advanced applications and traditional zeolite uses, are bright.

\subsection{Synthesis of bi-dimensional zeolites}

A particular form of nanosized zeolites is so called zeolite nanosheets. In this case the crystals are relatively large, but the thickness in one direction is one to several unit cells. Although not nanometric in all three directions, the zeolite nanosheets are included in this review since they exhibit particular properties that attracted a lot of interest over last 5 years.

The concept was first introduced by Corma and co-workers, who prepared such sheets by a top-down approach. ${ }^{42}$ A MWW-type zeolite precursor was subjected to treatment to swallow hexadecyltrimethylammonium and then delaminated by ultrasonic treatment. The same approach was used to delaminate FER- and NSI-type zeolite precursors. ${ }^{43,44}$

An in situ method for generation of zeolite nanosheets was reported by Ryoo and coworkers. ${ }^{45}$ A specific surfactant that comprised two quaternary ammonium groups separated by $\mathrm{C}_{6} \mathrm{H}_{12}$ linkage is used to promote the formation of MFI-type zeolite. The two quaternary ammonium groups are linked with long chain $\left(\mathrm{C}_{18} \mathrm{H}_{37}\right)$ alkyl group that suppress the growth of zeolite. Thus bi-dimensional zeolite crystals with thickness of one unit cell were synthesized. The extension of synthesis reaction leads to the formation of ordered multilamelar structures that are more appropriate for practical applications. ${ }^{46}$ Tsapatsis and co-workers demonstrated 
the possibility to synthesize nanosheets by replacing the surfactant with bi-functional structure directing agent. ${ }^{47}$

Shaped zeolite nanocrystals with three-dimensionally ordered mesoporous (3DOm) were synthesized and successfully used for preparation of oriented films. The ordered mesoporous carbon replicas were considered as attractive materials for carrying out confined synthesis of zeolite crystals with a wide range of crystal morphologies and size-tuneable crystallites, ranging between 10 and $40 \mathrm{~nm}^{48-50}$

After these pioneering studies different structure directing agents and synthesis conditions were explored to obtain zeolite sheets. ${ }^{51-55}$ The acidic properties and the potential of zeolite sheets were tested in a number of catalytic reactions. For instance, the selective formation of propylene from methanol over high-silica nanosheets was studied by $\mathrm{Hu}$ et al. ${ }^{56}$ The open highly accessible active sites of zeolite sheets are particularly appropriate for bulky molecules processing. Therefore, Lee et al. used such a catalyst for upgrading bio-oil derived from biomass constituents. ${ }^{57}$ Zeolite nanosheets produced bio-oil of better quality in respect to a reference Al-SBA-15 material. Tin-modified MFI nanosheets were used in Baeyer Villiger Oxidation to Cyclic Ketones, where they exhibited drastically higher thermal and hydrothermal stability in respect to a reference Sn-MCM-41 reference material. ${ }^{58}$

The list of the studies devoted on the preparation of zeolite sheets is much longer. Recent reviews covered the main achievements in the preparation of zeolite nanosheets and zeolites with bi-modal porosity (hierarchical zeolites) are available..$^{59,60}$

\section{Nanoclays}

\subsection{Properties of nanoclays}

Clay nanomaterials have been used long before their structure was determined and understood, as witnessed by the well-known example of "Mayan blue", a nanocomposite of indigo pigments and clay minerals. ${ }^{61-65}$ Although phyllosilicates like Laponite and Allophane form nanosized particles, the term 'nanoclays' is generally used to denote clays whose particles have at least one dimension, usually along the $c$ axis, in the nanoscale range (1-100 $\mathrm{nm})$. In this respect nanoclays resemble of zeolite nanosheets reviewed in the previous section.

The clays used for the preparation of their nanosized analogies belong in most of the reported cases to smectite group, which are also known as 2:1 phyllosilicates. The basic structural unit of the latter consists of an octahedral sandwiched between two tetrahedral sheets. Because of isomorphous substitution of $\mathrm{Al}^{3+}$ for $\mathrm{Si}^{4+}$ in the tetrahedral sheet and $\mathrm{Mg}^{2+}$ for $\mathrm{Al}^{3+}$ in the 
octahedral sheet, the layers of many clay minerals carry a negative charge, which is balanced by exchangeable alkali or alkali earth $\left(\mathrm{Na}^{+}, \mathrm{Ca}^{2+}\right)$ cations occupying the interlayer space. Clay mineral layers have the tendency to be stacked in face-to-face arrangement leading to particles with at least 10 stacked dehydrated layers. ${ }^{66,67}$ The aspect ratio, defined as the average ratio of the width to the thickness of the particles (length/diameter ratio), is an important characteristic for clay materials. Besides the ion exchange and adsorption capacity, this characteristic determines the ability of a clay mineral to exfoliate. The terms "exfoliation" and "delamination" are used to designate the separation between the planar faces of two adjacent layers. The layers may eventually become completely independent from one another, with a loss of crystallographic orientation. In this case each unit is then freely oriented in space. There is not clear distinction between these two terms but as recommended in the Handbook of Clay Science, ${ }^{66}$ in the present article we will use the term exfoliation to denote the stage when the separated clay units are isotropically dispersed in a solvent.

The term nanoclays is generally confused with nanocomposites based on clays minerals. Clay minerals have been used for a long time as nanofillers because they are easily available on all the continents at relatively low cost. Sodium-Montmorillonite appears as the most interesting smectite for bio-nanocomposite preparations, due to its tendency to swell in the presence of water. This feature favours the exfoliation of the layer silicates, therefore facilitating the access of biopolymers, which are hydrophilic compounds, to the interlayer space of the clay. However, the reinforcing ability of natural clays is poor due to their large particle thickness and low affinity to organic polymers. Therefore the conversion of natural clays in nanoclays has been developed in order to make them compatible with polymers. ${ }^{66}$

Depending on the exfoliation conditions nanoclays have a particle size varying from a few stacked layers up to much greater numbers. The degree of stacking strongly influences all basic characteristics of nanoclays.

The cation exchange capacity (CEC) is among the most important properties of clay minerals. The CEC represents the total amount of cations available for exchange at a given pH. It is commonly expressed as meq/100 $\mathrm{g}$ of calcined clay. Typical CEC values of 2:1 phyllosilicates vary from $20 \mathrm{meq} / 100$ for the group of Sepiolite-Palygorskite to $120 \mathrm{meq} / 100 \mathrm{~g}$ for Montmorillonite. The CEC is directly linked to the charge density of the layers, which itself corresponds to the density of isomorphous substitutions. ${ }^{68}$

The ability to swell in water or in any polar solvent is also a defining property of the smectite group of cationic clay minerals. Swelling is easily observable at the macroscopic level, by the formation of gel-like phases when water is added to clay minerals, with a large increase in 
volume as compared to the dry solid. A swelling index may be defined as the gel volume (in $\mathrm{mL}$ ) obtained per $10 \mathrm{~g}$ of clay mineral, and it may reach values of $25-30 \mathrm{~mL} / 10{ }^{69,70}$

The basal surface atoms of a 2:1 clay mineral are the oxygens of the Si tetrahedron. In the absence of isomorphous substitution and defect sites, the clay mineral surface is composed of oxygen atoms involved in $\mathrm{Si}-\mathrm{O}$ bonds. The latter have considerable covalent character and the surface is hydrophobic. Hydrophilicity is introduced by isomorphous substitution, involving the presence of the exchangeable cations, which are hydrophilic. ${ }^{71}$ The edges of clay particles should exhibit a different reactivity from that of basal planes similar to that of amphoteric oxides: surface group such as $\mathrm{Si}-\mathrm{OH}$ may react both with a proton (thus giving rise to $\mathrm{Si}-\mathrm{OH}_{2}{ }^{+}$in acidic conditions), or with a hydroxide (thus giving rise to $\mathrm{Si}-\mathrm{O}^{-}$in basic conditions). The amphoteric behaviour means that clay minerals have acid-base properties; aqueous smectite dispersions have $\mathrm{pH}$ values from 7.5 for Montmorillonite to 10 for Laponite. Smectites possess two types of specific surface area, external and internal. The external surface area is the basal and lateral area constituted by layers stacking. The external surface varies from 30 to $130 \mathrm{~m}^{2} \mathrm{~g}^{-1}$ depending on the size and aspect ratio of the considered clay mineral. The internal surface corresponds to the basal surface of the layers that are "stuck" together. $^{72}$

For porous clay minerals, lenticular pores are often observed by TEM. The pores can be accessible or not depending on physicochemical characteristics of a nanoclay, but also on the preparation conditions such as for instance air- or freeze- drying processing. ${ }^{72,73}$

In addition, each clay material has particularities, which influence their properties and determine their use. For instance smectites display a complex rheological behaviour when dispersed in an aqueous medium. They form viscous gel phases at low volume fractions, a property which is widely exploited in industries. ${ }^{74}$

\subsection{Synthesis of nanoclays}

The major problem in the use of natural nanoclays is the presence of a mixture of several phases. To overcome this inconvenience synthetic methods for production of clay minerals have been developed. A lot of research was devoted to the synthesis of well-crystalline clay minerals with controlled composition and properties. The syntheses are performed under hydrothermal conditions that involves, similarly to zeolites, a nucleation and a crystal growth stages. The crystallization temperature is usually between 150 and $220{ }^{\circ} \mathrm{C}$ under autogenous pressure. In particular cases the pressure can reach up to 1500 bars. Syntheses performed at lower temperatures are not efficient and provide products of low quality. ${ }^{75}$ Similarly to 
zeolites the initial system composition, the nature of the reactants and temperature/time conditions are the key parameters governing the synthesis of clays. The major difference between zeolite and clay syntheses is that the latter can be formed at low $\mathrm{pH}$. A typical example is the Montmorillonite that can be obtained in acidic medium. ${ }^{76-79}$ Low pH (2-6) favours also the formation of 1:1 clay minerals such as kaolinite. In basic medium but at moderate $\mathrm{pH}$ (7-10 for $\mathrm{Al}^{3+}$, up to 12 for $\mathrm{Fe}^{3+}$ ) usually 2:1 clay minerals such as smectites and micas are formed. High $\mathrm{pH}(>12)$ favours the formation of zeolite in the presence of with $\mathrm{Al}^{3+}$ or aegerine in the presence of $\mathrm{Fe}^{3+}$ minerals.

The most often synthesized nanoclays is Laponite. The synthetic Laponite exhibits nanosized dimensions in all three directions. The synthesis of Laponite involves combining sodium silicate, magnesium, sodium and lithium salts to produce a hydrogel, which is subjected to hydrothermal treatment at $200{ }^{\circ} \mathrm{C} .{ }^{67}$ Synthetic Laponite is a nanomaterial of disc-shaped platelets, much smaller than naturally occurring counterpart. Compared to the natural product the synthetic Laponite exfoliates much easier.

Nanosized Imogolite and Halloysite are also obtained in nanosized form, but similarly to exfoliated clay minerals they are nanosized only along the $c$ axis. A specific feature of synthetic Imogolite and Halloysite is the formation of nanotubes. The first synthesis of Imogolite nanotubes was reported by Farmer et al. ${ }^{80}$ The freeze dried product had a cottonlike appearance. ${ }^{81}$ Halloysite nanoparticles with tubular structure have also been synthesized. ${ }^{82}$ Halloysite is an aluminosilicate clay mineral with chemical formula of $\mathrm{Al}_{2} \mathrm{Si}_{2} \mathrm{O}_{5}(\mathrm{OH})_{4} \mathrm{H}_{2} \mathrm{O}$ that belongs to the 1:1 phyllosilicates.

\subsection{Nanoclays by exfoliation}

There are several routes to exfoliate clay-type materials based on chemical and/or physical processes. A largely used chemical process is based on the intercalation of polymers or biopolymers. Several examples have been reported in literature, all of them require the modification of the clay mineral by organic moieties in order to be more compatible with the polymers.

Intercalation reactions can occur according to several routes depending on the nature of the compound intercalated. Neutral organic molecules can be adsorbing by complexation of the interlayer cations, ion-dipole interaction, acid-base reactions, charge transfer, van der Waals forces or H-bonding. However, the use of charged species such as alkylammonium cations is the most often used approach for pre-treatment of clays prior to the exfoliation step. 
Grafting different organic moieties of clay surface is commonly used approach prior to polymer intercalation. ${ }^{66}$ The most successful one is the grafting of organosilanes. The covalent bonds established by condensation of some reactive groups on the organic chain with the clay silanol surface groups or with the hydroxyl groups of octahedral layer as in the case of kaolinite allowing the expansion of the interlayer space. Consequently, the surface becomes hydrophobic and compatible with the polymers required to exfoliate. It differs from ion exchange procedures by the creation of covalent bonds between the clay mineral surface and the silsesquioxane. This results in irreversible organophilization, while intercalation by ion exchange is usually reversible.

"Acid activation" or "acid dissolution" is reported to facilitate the exfoliation. During the acid treatment, the surface of clay is protonated on the edge groups while introducing $\mathrm{H}_{3} \mathrm{O}^{+}$cations in the interlayer space. The acid treatment leaches metal ions, usually from the octahedral layer first. It also increases the external surface area of the clay and introduces permanent mesoporosity. ${ }^{83}$

Among the physical methods, ultrasonic radiation has showed excellent results in the exfoliation of clay minerals compared to other mechanical methods. After sonication, significant delamination and lateral size reduction in phyllosilicates occurs. ${ }^{84,85}$ The products retained their crystalline structure and their morphology. However, when the interactions between the layers and the interlayer space are strong enough, treatment by sonication is clearly not sufficient and other physical or chemical methods should be applied.

Some patents reported on the use of supercritical fluids (SCFs) to exfoliate silicate minerals. In this process, silicate mineral particles are dispersed in SCFs to diffuse fluids into the interlayer space, followed by rapid depressurization or cooling to gasefy the SCFs. The expansion of SCFs in the interlayers breaks the interlayer forces resulting in exfoliation of the silicate minerals. $^{86}$

A freeze-drying approach has been developed for the exfoliation of clay minerals. ${ }^{87}$ It consists in the nucleation and propagation of ice crystals in the interlayer space. ${ }^{88-91}$ The expansion of the layers and the cracks remained after the water sublimation change substantially the properties of the clay mineral.

The generation of nanoclay minerals by combining chemical and physical treatments is schematically presented in Figure 5. First, an organophilisation is performed by the intercalation of cationic surfactants or polymers. The resulting composites are then freezedried or sonicated in order to reach a high level of exfoliation. 


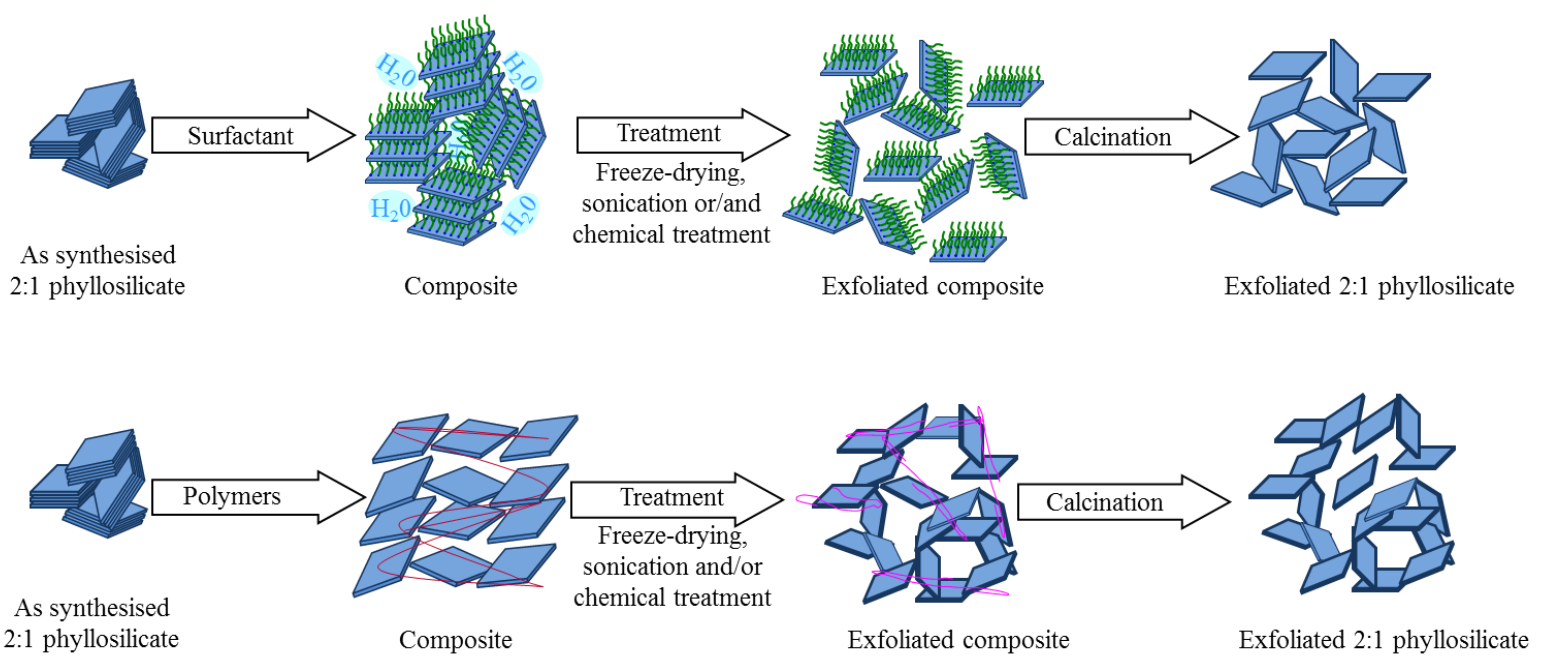

Figure 5. Preparation of clay minerals by exfoliation.

The exfoliation process significantly changed the basic characteristics of nanoclays. Substantial changes in physical and chemical properties require the use of complementary physical and chemical methods for analysis. Usually a combination of transmission electron microscopy, X-ray diffraction, SAXS, vibrational and NMR spectroscopy combined with sorption measurements are used to obtain a complete picture of the changes in the structure and properties of exfoliated nanoclays. ${ }^{92-98}$

A summary of all nanosized zeolite, zeolite nanoshetes and nanoclays synthesized up to now is presented in Figure 6.

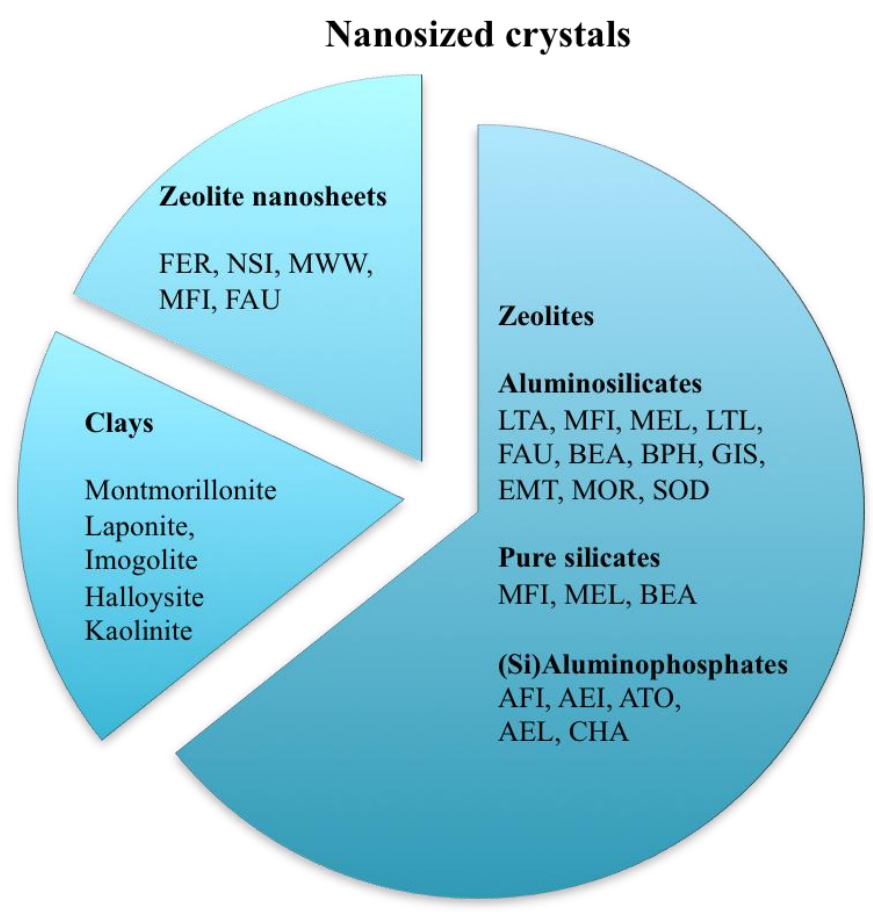


Figure 6. Synthetic nanosized zeolites (19 types), zeolite nanoshetes (5 types) and nanoclay (5 types).

\section{Applications}

\subsection{Nanosized zeolites}

The potential uses of nanosized zeolites and nanoclays are going much beyond traditional catalysis, sorption and ion exchanges processes. These materials are considered in a number of advanced applications, where namely bulk materials were used. Recent developments of synthesis procedures for nanosized zeolites and their arrangements in thin-to-thick films, membranes and hierarchical forms have pushed them into new and advanced applications that have not been considered before. ${ }^{99-107}$ The following sections provide a comprehensive overview of the use of nanosized zeolites for nanotechnology applications including sensors, optical layers, medicine, pharmaceutical industry, cosmetics and food.

\subsubsection{Sensors based on nanosized zeolites}

The global market for gas sensors is expected to reach $\$ 2,512.4$ million by 2020 , according to a market report by Grand View Research Inc., driven largely by new regulatory initiatives. ${ }^{108}$ The adsorption capacity, high-surface area and porosity, presence of mobile ions, and catalytic activity make zeolites attractive candidates for chemical sensing/detection. In addition, nanosized zeolites offer a fast response and facile processing that make them particular appropriate for sensing devices. Consequently many fabrication methods were used in the production of zeolite-based chemical sensors. Common techniques for preparation of sensors include (1) direct growth with and without pre-seeding of the substrates, (2) sol-gel techniques, (3) screen-printing, (4) dip and spin coatings, and very recently (5) ink-jet deposition (Figure 7). A review analysing in depth the techniques for preparation of microporous thin film is available. ${ }^{109}$ The primary challenge in utilizing nanosized zeolites remains the ability to fabricate or pattern thin films with appropriate micro-nano-scale features. The attractive properties of zeolites combined with the ability to choose and adept an appropriate patterning technique is expected to enhance their utilization in device fabrication. In the chemical sensors devices, the zeolite may act as a main functional element, which is the case for sensor principles relying directly on conductive, adsorptive, or catalytic properties of one specific type molecular sieve and its interaction with the analytes. The zeolites can also be included as supplementary or secondary element in the device. 


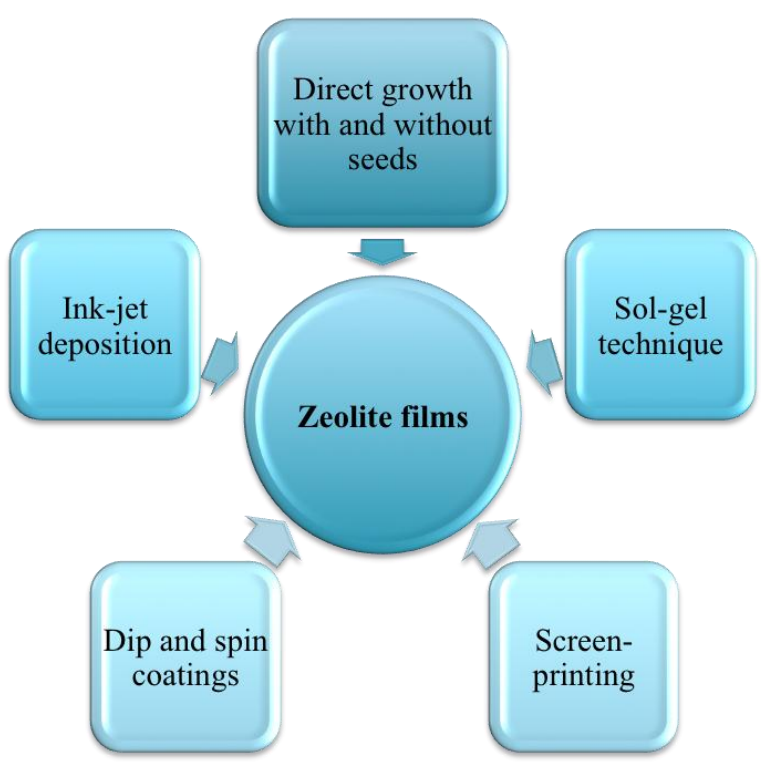

Figure 7. Techniques applied for preparation of zeolite-based sensors.

Microporous materials (zeolites or clays) offer versatility in terms of structures and chemical compositions. Size and shape selectivity toward different analytes is generally improved through control of the dimensions and shapes of the pores enabling detection and discrimination between different molecules. Chemical selectivity and sensitivity of zeolitebased sensors can also be controlled by changing the chemical composition of nanosized zeolites from pure silica to highly-aluminium containing zeolites thus going from highly hydrophilic to hydrophobic materials. Besides, the incorporation of selected dopants such as metals, metal oxides, metals sulphides and organics into the zeolite frameworks can further improve selectivity of the materials. Indeed, the defined zeolite pore structure makes them attractive as true shape-selective materials (Figure 8).

Several review papers on zeolites-based sensors have been recently published. ${ }^{5,105,110-112} \mathrm{~A}$ large varieties of zeolites have been deposited on sensor devices, and a large number of analytes have been investigated. The zeolite-based sensors for exhaust gases, chemical and biological molecular species will be further revealed in this paper. The main advantages of nanosized zeolites for sensor applications are due to: (i) achievable stabilization in coating suspensions, (ii) possibility to deposit in thin films via different approaches, (iii) miniaturization of sensor devises, (iv) decrease of detection time and saturation for analytes by decreasing the thickness of zeolite films, and (v) improve of accessibility and selectivity via introducing preferred orientation of zeolite nanocrystals in the films. 


\section{Zeolite-based sensors for exhaust gases}

Zeolite-based sensors for exhaust gases detection including nitrogen oxides $\left(\mathrm{NO}_{\mathrm{x}}\right)$, carbon monoxide ( $\mathrm{CO})$ and carbon dioxide $\left(\mathrm{CO}_{2}\right)$, hydrocarbons mainly including methanol, ethanol, aldehydes and alkanes, ammonia $\left(\mathrm{NH}_{3}\right)$, hydrogen sulphide $\left(\mathrm{H}_{2} \mathrm{~S}\right)$, sulphur dioxide $\left(\mathrm{SO}_{2}\right)$ and hydrogen $\left(\mathrm{H}_{2}\right)$ were presented in a recent review. ${ }^{110}$ The sensing devices have to be electrically conductive, catalytically selective, and electrochemically active. In addition, the devices have to be highly long-term stable in the harsh environment conditions. ${ }^{113}$ Therefore, various materials combining all these functions in one configuration are required.

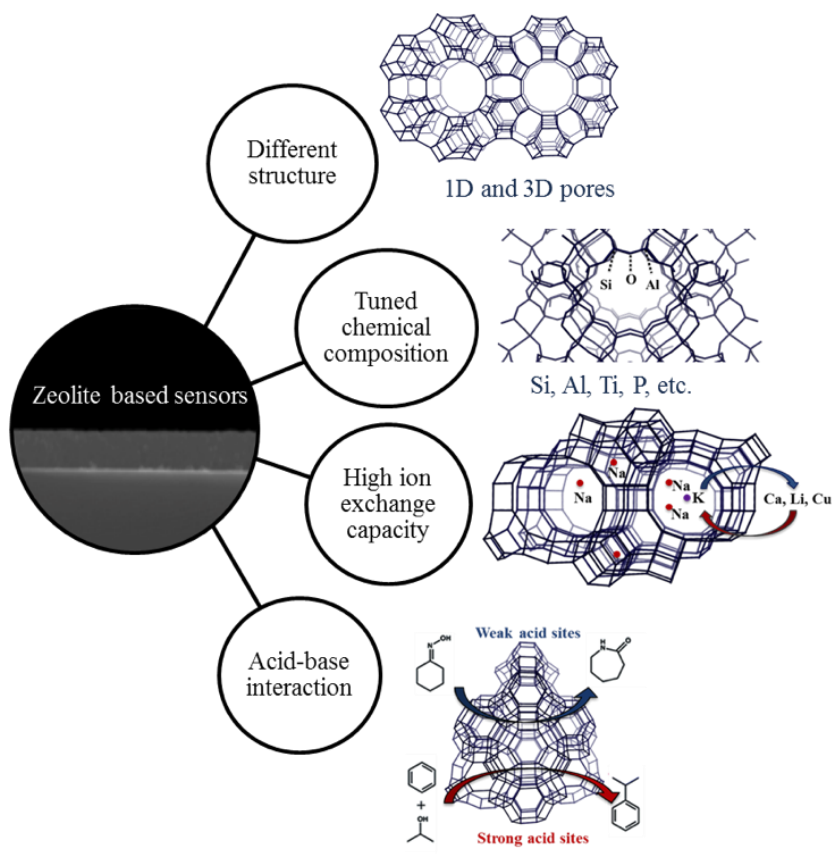

Figure 8. Shape-selective chemical sensors controlled by zeolites.

Dutta et al. reported on the development of sensors based on a $\mathrm{Ru}(\mathrm{II})$ bipyridyl complex in FAU zeolite as a visual probe for detection of oxygen in macrophage cells. ${ }^{114}$ The ruthenium complex in the FAU type zeolite has long-term stability and sensing capacity. ${ }^{115}$ Additionally, thin zeolite films were used to cover conducting sensing electrodes to selectively limit $\mathrm{CO}_{2}$ exposure to the sensing surface. As the diffusion of oxygen through the zeolite film is preferential to that of $\mathrm{CO}_{2}$, the coated sensor showed a marked drop in response towards $\mathrm{CO}_{2}$ along with slightly diminished but still discernable response towards $\mathrm{O}_{2}{ }^{116}$

Efficient $\mathrm{NO}_{\mathrm{x}}$ detection was performed by conductive metal oxides $\left(\mathrm{WO}_{3}, \mathrm{ZnO}\right.$, etc.) covered with different zeolites. ${ }^{117}$ The FAU zeolite films deposited on the metal oxide showed faster response towards $\mathrm{NO}_{2}$ in comparison to the $\mathrm{WO}_{3}$ pure sensor. Similar results were obtained for $\mathrm{ZnO}$ covered with zeolite films, and the sensitivity of the sensor increased substantially 
too. ${ }^{118}$ Further the sensitivity of the sensors toward $\mathrm{NO}_{\mathrm{x}}$ was improved via using Pt doped FAU zeolite crystals. ${ }^{119}$

The detection of $\mathrm{CO}$ and $\mathrm{CO}_{2}$ is a major target for sensing, which is based on either metal oxides encapsulated in zeolites or in polymer/zeolite composites. The ferrierite (FER) layers showed enhanced sensitivity towards $\mathrm{CO}$ at $300{ }^{\circ} \mathrm{C}$, while semiconducting tungsten oxide and chromium titanium oxide covered with zeolite were found to be sensitive to CO. ${ }^{120}$ Additionally a polyaniline/zeolite (Ca-LTA) sensor with high selectivity towards CO was reported. ${ }^{121}$ The Ca-LTA zeolite exhibits more accessible pores than the K- and Na- forms, and it has shown to have no great influence on the diffusion of $\mathrm{CO}$ through the conductive polymer. Another report was on the utilization of poly(3,4-ethylenedioxythiophene) doped with polystyrene sulfonic acid and ZSM-5 zeolite crystals. The sensitivity increased when the Si/Al ratio of the ZSM-5 zeolite decreased. ${ }^{122}$ Recently, we also demonstrated that metalcontaining zeolite Beta with high selectivity towards $\mathrm{CO}$ in the presence of water can be prepared. ${ }^{123,124}$ The high sensitivity of the Pt- and Pd-zeolite films to CO in very low concentrations (2-100 ppm) in the presence of highly concentrated vapours of methanol or pentane (400-4000 ppm) was reported.

A composite based on FAU zeolite crystals grown on a Metglas magnetoelastic strip for $\mathrm{CO}_{2}$ sensing has also been developed. ${ }^{125}$ In this case, a dry atmosphere was required to avoid the interference with water. A similar device was prepared by the same group using hydrophobic pure silica MFI type zeolite (silicalite-1). The device was used for sensing of $\mathrm{CO}_{2}$ in air thus avoiding the use of nitrogen.

\section{Zeolite-based sensors for hydrocarbons}

A very extensive research has been devoted to the selective chemical sensing of hydrocarbons using zeolite films. Many different framework-type microporous materials were used to sense and capture hydrocarbons and volatile organic compounds (VOCs). ${ }^{126}$ The detection of VOCs and hydrocarbon by zeolites layers considering mainly the detection limit and stability under different conditions were reported. ${ }^{127,128}$ Tungsten and zinc oxides covered with zeolite film have also been described as excellent ethanol sensors. ${ }^{118}$ The oxide sensors covered with LTA type zeolite showed selectivity toward ethanol in comparison to isopropanol. ${ }^{117}$ The conductive polymer (polypyrrole, polyamide-6) combined with K-LTA zeolite crystals were applied for sensing of acetone, methylether ketone, methanol, and toluene. ${ }^{129}$ Selective detection of $n$-butane in the presence of $i$-butane using zeolites was reported too. ${ }^{130}$ A zeolite sensor showed the lowest detection for $o$-xylene $(6 \mathrm{ppm})$, however the sensor suffered from a 
lack of selectivity with cross-sensitivity to $p$-xylene. ZSM-5 crystals doped with Pt and Au showed a great selectivity toward propane and propylene. ${ }^{131}$ The best performance of the sensors was obtained using zeolite layers with high silica content, as well as using thin layers with properly oriented crystals. ${ }^{132,133}$ High silica MFI film was reported for the detection of isopropanol (16 ppm) and toluene (22 ppb). The fast response toward isopropanol than for toluene was presented, which was explained with the smaller size of the former molecule. ${ }^{134}$ Metal containing ( $\mathrm{Pt}, \mathrm{Fe}$ ) MFI and FAU type zeolite films showed a strong cross-sensitivity to several analytes including $\mathrm{NO}, \mathrm{CO}, \mathrm{CO}_{2}$, ammonia, and hydrocarbons with low concentration (1-5 ppm). ${ }^{135}$ The highest sensitivity toward ammonia was reported for Fe containing MFI zeolite layers, which was explained by the high acidity, pore volume and surface area of the zeolite. The preparation of reversible $\mathrm{NH}_{3}$ sensors comprised of $\mathrm{HClO}_{4}$-doped poly(3thiopheneacetic acid) polymer with FAU type zeolite crystals gave excellent results. ${ }^{136}$ Very recently, the potential of $\mathrm{Ag}$ loaded FAU zeolites for $\mathrm{NH}_{3}$ detection based on the mobility change of the silver cations $\left(\mathrm{Ag}^{+}\right)$in the presence of $\mathrm{NH}_{3}$ were presented. ${ }^{137}$ No crosssensitivity for $\mathrm{O}_{2}, \mathrm{CO}, \mathrm{CO}_{2}$ and propane was measured.

The effect of acidity and pore diameter of zeolites on the detection of base molecules including water, acetonitrile, ammonia, benzonitrile, pyridine, aniline, and triethylamine was investigated. It was pointed out that acid-base interaction is the major factor when molecular diameter is smaller than the zeolite pore diameter (Figure 8). As for larger molecules (benzonitrile, pyridine, aniline, and triethylamine) of which the molecular diameter is nearly the pore diameter of zeolites, the response magnitudes were lower than those of the smaller molecules. ${ }^{138}$ The sensitivity of the zeolite sensors to various base molecules as a function of proton affinity, which can be regarded as a measure of base strength of the molecules have been investigated. The sensitivity generally increased with the increase in the proton affinity. In the case of large molecules such as pyridine and triethylamine, the sensitivity was strongly dependent on the type of zeolites (MOR > BEA > MFI) indicating the significant contribution of diffusion in the detection of larger molecules. ${ }^{139}$ Additional functionality in the zeolite sensors has been introduced via using their ion-exchange capacity (Figure 8) and thus the selectivity towards desired molecules was achieved. It was found that the propane sensor effect takes place at the zeolite/Au electrode and was controlled by bulk diffusion of propane into the pores of the zeolite. ${ }^{140}$

\section{Zeolite-based biosensors}

A human breath analysis was performed with twenty sensors connected in series for the 
diagnosis of asthma since NO in breath increases from 5-10 ppb (normal state) to $100 \mathrm{ppb}$ in an asthmatic state. ${ }^{141}$

Zeolite nanocrystals were also applied to enrich and identify low-abundance peptides/proteins, as well as to immobilize enzymes for bio sensing. ${ }^{142}$ Magnetically separable nanosized zeolites were fabricated by combining their surface properties with the super paramagnetism of $\mathrm{Fe}_{3} \mathrm{O}_{4}$ nanoparticles. Attractive perspectives in bio-applications such as magnetically controllable biosensors and microfluidic biochips were considered. ${ }^{143}$

The development of oxygen-enhanced membrane assemblies suitable for use in sensors and biosensors involving oxygen for the detection of the targeted substance was reported. ${ }^{144}$

Great attempts were focused at the evaluation of the adsorption efficiency of zeolites versus toxins in different media. ${ }^{145-147}$ A removal of uremic toxins by adsorption process (e.g. during the hemodialysis) using zeolites instead of conventional polymer membranes was reported. ${ }^{146,148}$ The high toxicity of p-cresol or 1,4-methylphenol responsible for the intoxication of patients, ultimately causing heart attack due to increased serum concentration, was studied. ${ }^{149,150}$

Recently we studied the detection limit for uremic toxins such as o- and p- cresol with EMT, LTL and MFI type zeolites assembled in thin films. Low concentrations of o- and p-cresol (5$50 \mathrm{ppm})$ in the presence of water vapour (100 ppm) with the three-zeolite films were detected. Between the three zeolites, the EMT shows the fastest response and saturation for o- and pcresol at low concentration (5 ppm), while the pure silica MFI film had the highest sorption capacity due to its hydrophobic nature.

Impedance-based detection of highly toxic organophosphate nerve agent Sarin in the presence of dimethylmethylphosphonate (DMMP) using FAU type sensors was investigated. ${ }^{151}$ The surface of the zeolite had negligible effects on the decomposition of DMMP, while the intrazeolite cations motion facilitated by the DMMP reorientation was found to be responsible for the decrease in the impedance. The cations with larger size in the supercage of FAU zeolite showed an increase in impedance when exposed to DMMP, probably due to the repulsive interactions that counteract the ionic motion. The change in the Na-FAU impedance was used as a sensor for detection of organophosphates at elevated temperature. The selectivity to DMMP in the presence of other molecules including methane and propane was found to increased. $^{151}$

The concept of physically and functionally integrating zeolite films with the long period fiber grating (LPFG) had offered new opportunities in the development of a variety of chemical sensors with high sensitivities for detection of chemical and biological molecular species. The 
advantages of this type of sensors were mentioned to be operation simplicity, and compactness, which are highly desirable for portable device applications. ${ }^{134}$

Optical devices to measure the change in optical reflectivity upon adsorption of chemical and biological molecular species were designed too. In recent years, colour tuneable Bragg stacks composed of various materials, including hydrogels, inorganic materials such as silicon, titania, silica etc. were found to be responsive to a wide variety of analytes through optical thickness variations of the specific nanostructures. ${ }^{152-154}$ The unique combination of chemical and optical properties of nanosized zeolite crystals opened up the possibility of using them as a part of tuneable Bragg stacks. The porous Bragg stacks are considered for chemical sensing application with optical encoding. The idea behind is that the change of refractive index and/or thickness of the layers in the Bragg stack will be due to ion-exchange, sorption, and capillary condensation of molecules adsorbed in the pores which will result in a shift of the high reflectance band and consequent change of their colour will be observed. ${ }^{155-157}$ Recently we have shown that by using materials with high optical contrast such as $\mathrm{GeSe}_{2}\left(n_{H}=2.65\right)$ and nanosized zeolites $\left(n_{L}=1.19\right)$, it is possible an omnidirectional reflectance to be obtained. ${ }^{158}$ However finding porous materials with high refractive index is not a trivial task. To overcome this problem, the preparation of quasi-omnidirectional (q-ODR) photonic crystals (PhC) exhibiting high reflectance for all polarization but in narrower range of incident angles as compared to omnidirectional $\mathrm{PhC}$ was considered. Additionally, the preparation of onedimensional photonic crystals based on MEL type nanosized zeolite and $\mathrm{Nb}_{2} \mathrm{O}_{5}$ was reported. ${ }^{153}$ MEL type zeolite nanocrystals were used for both sensing and transducing elements, while the sufficient optical contrast is ensured by sol-gel derived $\mathrm{Nb}_{2} \mathrm{O}_{5}$ film. The particular choice of MEL type nanosized zeolite was made considering their hydrophobicity and high sensitivity towards acetone. The sensing properties of the multi-layered structures toward acetone were studied by measuring transmittance spectra prior and after vapour exposure. The adsorption/desorption cycles of acetone with photonic crystals based on different number of $\mathrm{Nb}_{2} \mathrm{O}_{5}$ and MEL zeolite layers are presented in Figure 9. 
(a)

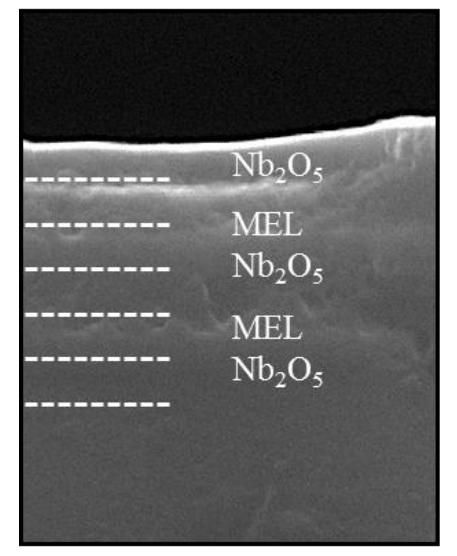

(b)

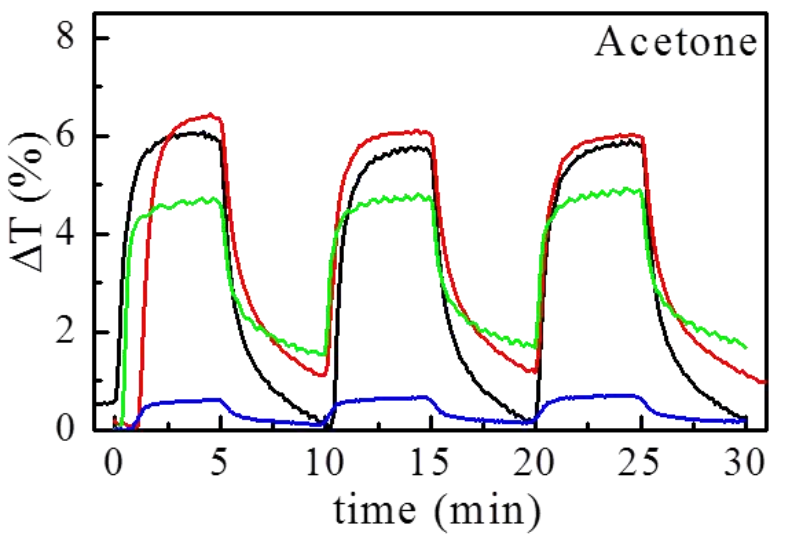

Figure 9. (a) SEM picture of multi-layered sensor consisting of $\mathrm{Nb}_{2} \mathrm{O}_{5}$ and MEL type nanosized zeolite, (b) kinetics of transmittance changes for a sensor comprising 2 (blue line), 3 (green line), 5 (black line) and 7 (red line) alternating $\mathrm{Nb}_{2} \mathrm{O}_{5}$ and MEL zeolite films within 3 cycles of adsorption and desorption of acetone at room temperature.

After switching on and off the acetone vapour, a fast adsorption and desorption, respectively took place, followed by steady state signal. Besides, a fast recovery without additional annealing was observed that opens up the possibility for preparation of sensors with optical read-out by incorporation of the sensitive and the transducer elements in a single device.

Biosensors for the amperometric detection of hydrogen peroxide based on the coimmobilization of horseradish peroxidase and methylene green on a zeolite-modified glassy carbon electrode, avoiding the commonly used bovine serum albumen glutaraldehyde, was presented. ${ }^{159}$ The presence of zeolite resulted in high enzyme and mediator loading. The zeolite-based sensor was suitable basis for biologically important substances, i.e., horseradish peroxidase can catalyse different reactions including peroxidation, oxidation, dismutation, and hydroxylation. Thus the hydrophilic character of zeolites, the soluble enzyme and methylene green retaining in the zeolite film greatly improved the stability of the sensor. ${ }^{160}$ Quartz crystal microbalances (QCMs) devices covered with silver ion exchanged ZSM-5 films demonstrated high sensitivity to acetone vapour (bellow $1 \mathrm{ppm}$ ), with an average response of $90 \mathrm{~s}$. The reproducibility of the data below $45^{\circ} \mathrm{C}$ was high, which can be used to distinguish the healthy breath from the diabetic ones. ${ }^{161}$

Photopolymers doped with different nanosized zeolite have demonstrated selective sensing behaviour toward toluene, water, linear and branched hydrocarbons. ${ }^{162-165}$ The glass or 
plastic substrates were covered with nanosized zeolites and exposed directly to the environmental conditions. ${ }^{162-165}$ Absorption of gases (hydrocarbons, $\mathrm{CO}, \mathrm{CO}_{2}, \mathrm{NO}, \mathrm{NO}_{2}$ ) by reflection gratings recorded in an acrylamide-based films doped with nanosized zeolites resulted in reversible adsorption, and the resultant change in periodicity of the reflection grating caused a shift in the reconstructed wavelength. The same principle has been adopted for the development of liquid-phase alcohols and $\mathrm{pH}$ sensors. The sensing ability of transmission gratings recorded in zeolite-doped acrylamide photopolymer layers have been studied from the same group. Polymers doped with high silica zeolites (BEA, MFI and MEL) were used for detection of alcohols, which are one of the most widely used groups of chemicals in research and industry, as they have important application as solvents and play an important role in the production of other chemicals. Therefore the development of sensitive and selective alcohol sensors is of great interest. The developed optical sensors have advantages over other sensor types such as semiconductor and electrochemical sensors due to their potential for fast response times and high gas specificity, as well as allowing for labelfree, in-situ, real-time measurements.

The variety of chemical sensors using different zeolites developed during the resent years is disclosed in Figure 10. As can be seen, mainly 6 types of zeolites with LTA, MFI, LTL, BEA, MOR, and EMT type structures were applied for the preparation of chemical sensors.

\section{Zeolite-based sensors}

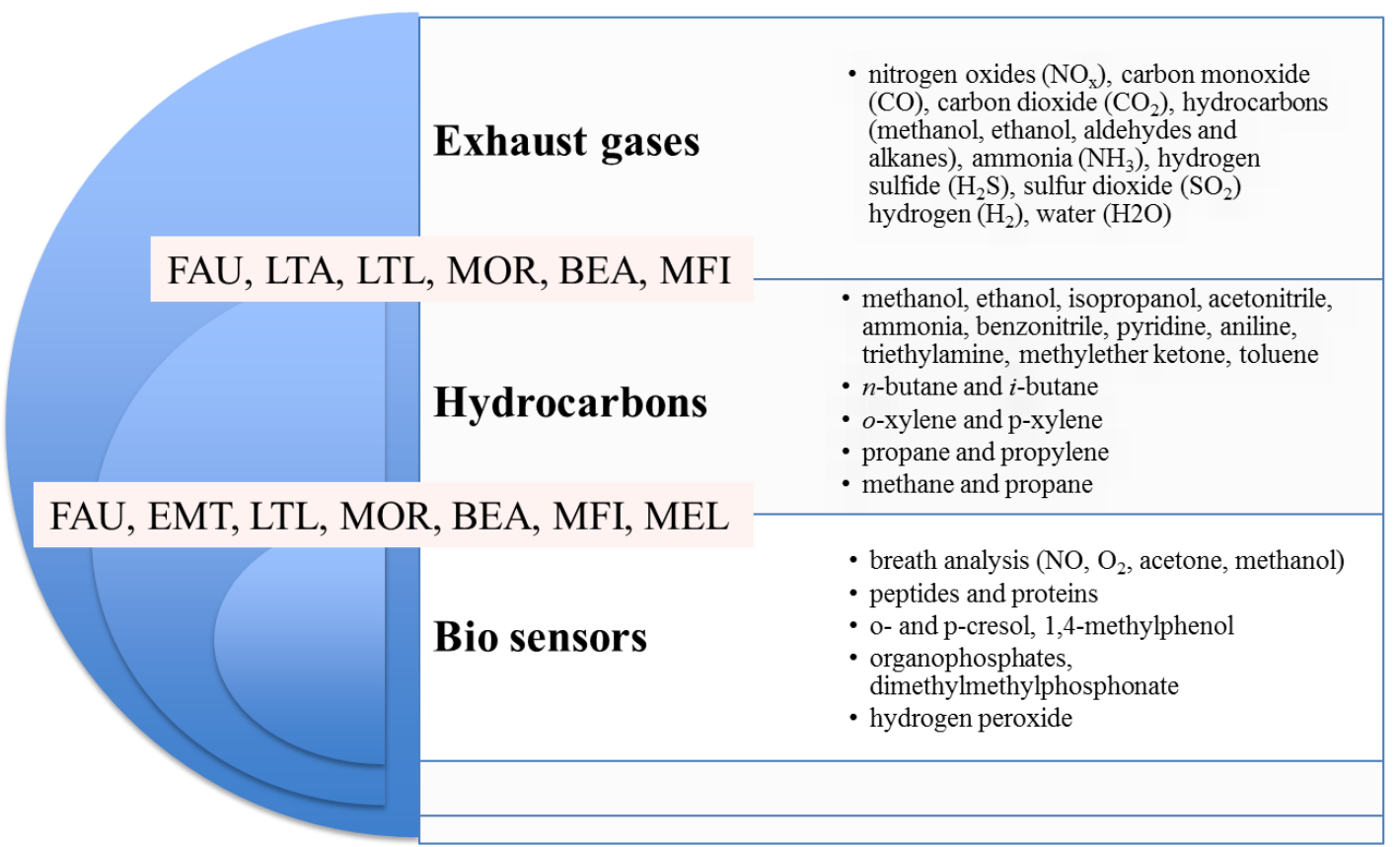


Figure 10. Chemical sensors based on nanosized zeolites.

\subsubsection{Other devices based on nanosized zeolites}

The fabrication of optical devices using nanosized zeolites attracted considerable attention due to their rigid structure, high thermal stability and availability in different morphologies. Zeolite films are used for preparation of optical quality films with a thickness in the range 50$170 \mathrm{~nm}$ through spin-on or sol-gel deposition methods. ${ }^{99,100}$ The optical properties of the zeolite films including refractive index, extinction coefficient, thickness, and hardness were found to depend on the method of preparation and on the use of different binders with organic vs. inorganic natures. The free pore volume of the zeolite films was found to depend on the type of the crystalline structure and chemical nature of binders.

The encapsulation of organic dyes in the channels of one-dimensional LTL nanosized zeolite for light harvesting and energy transfer was presented as an original model of zeolite-based photovoltaic solar cell. ${ }^{166}$ Multilevel organization of zeolite crystals of $40 \mathrm{~nm}$ in hybrid films for optoelectronic applications was reported from the same group. The functionalization of the zeolite surface resulted in different organizations inside the zeolite cavities and on the outer surface of the polymeric structure. The ordered LTL films allowed arrangement of single dye loading in the zeolite cavities with a conjugated polymer. The hybrid films contained three levels of organization: (1) organization of the dye molecules in the one dimensional LTL zeolite channels, (2) organization of the zeolite crystals inside the polymer cavities, and (3) micro- or nano-structuration of the polymer. ${ }^{167}$ The working principal was based on the absorption of light by the dye-zeolite composite containing semi conductors, which is responsible for the electron-hole formation. Another concept was based on $\mathrm{TiO}_{2}$ introduced in the cages of FAU type zeolite and modified by organic acids or nitrogen doping. ${ }^{168}$ The photovoltaic activity with the doped FAU zeolites were 20 times less compared to the pure $\mathrm{TiO}_{2}$ based solar cells. However, considering the low loading of titanium dioxide within the zeolite $(4.8 \%)$ this photovoltaic activity was considered as relatively strong.

New photovoltaic solar cells based on quantum dots (QDs = CdS and PdS) encapsulated in the voids of FAU zeolite were presented. ${ }^{169}$ The results showed that the activity of devices depends on the type of the QDs, and the best performance was obtained for FAU type crystals doped with more than one type of quantum dots. In addition, Ag nanoparticles selectively deposited in the channels or on the surface of nanosized zeolites with one- and threedimensional pore structures were considered for the same application. 
Zeolite films were applied as corrosion resistant layers too. ${ }^{170} \mathrm{~A}$ review on the advanced application of zeolites including semiconducting industry and space stations was published. ${ }^{103}$ The emphasis was given on the development of zeolite films as low-dielectric constant layers for (i) future generation computer chips, (ii) environmentally benign corrosion-resistant coatings for aerospace alloys, and (iii) hydrophilic and bacteriological coatings for gravityindependent water separation in space stations. Numerous examples were presented for zeolites exhibiting either hydrophobic or hydrophilic properties with low or high ion exchange capacity, respectively. The zeolite layers show great mechanical stability and hardness, which make them interesting for reverse osmosis membranes for seawater desalination and proton exchange membrane fuel cells.

\subsubsection{Biological and medical applications of nanosized zeolites}

The increasing utilization of engineered nanoparticles for a range of application in fields such as electronics, photonics and biomedicine demands an assessment of risk associated with deliberate or accidental exposure. Major health concerns in relation to exposure to nanoparticles arise from the same property which is of great importance for their potential industrial applications, that is, the characteristic of high surface to mass ratio and potentially high surface adhesion and reactivity compared to their larger counterparts. However, for many applications the toxicology of the nanomaterial has not been addressed, although its importance is now being realized. The cytotoxicity of inorganic nanoparticles such as zeolites, metals and metal oxides is gradually recognized as an important issue in "nanosociety". Nanoparticles in general may have an adverse effect on human health compared to their micrometer counterparts and therefore nano-safety regulations may become necessary.

Nanoparticles can enter the human body via: (i) the lungs where a rapid translocation through the blood stream to vital organs is possible, including crossing the blood brain barrier (BBB), and absorption, (ii) the intestinal tract, or (iii) the skin.

The interest in the toxicity of zeolite nanocrystals is very high due to their wide use in industry and commercial products. One of the reasons for zeolite nanoparticles not to be extensively studied for their biocompatibility is a relatively low occurrence of direct contact with humans. A recent review on the synthesis and commercial potential of microporous nano-materials for environmental applications connected with biological toxicity was published. ${ }^{171}$ Studies on the biocompatibility of zeolite coated on commercially potent titanium to pluripotent mouse embryonic stem cells were performed and it was found higher adhesion and rate of cellular proliferation. ${ }^{172}$ However, since different cells demonstrate 
different types and magnitude of responses on exposure to nanoparticles, it is important to analyse the response of human cells on exposure to various nanosized zeolites.

The nanosized zeolites free of organic templates show no or very low toxicity to the HeLa cells. ${ }^{173-175}$ The low cytotoxicity of the nanosized LTL type zeolite was reported. ${ }^{176}$ At high concentrations a toxic response was observed, which was explained with the active positively charged crystalline surface. However, the pure silica zeolites, or low Al containing zeolites were reported to be non-toxic no matter the amount used. All measurements were carried out with HeLa cancerous cell line. ${ }^{177}$ It was concluded that the nanosized zeolites had good thermal and chemical stability due to their highly crystalline structures, and their toxicity differences on HeLa cell had to be mainly depend on their sizes, shapes and surface properties rather than the release of their toxic species.

Kihara et al. investigated the toxicities of nanosized zeolites with LTA, MFI (both ZSM-5 and silicalite-1) and LTL type structures using human embryonic kidney 293 (HEK-293), RAW264.7 macrophage and HeLa cells. ${ }^{177}$, The toxicities of zeolite nanoparticles were found to be dependent on their size $(30-500 \mathrm{~nm}), \mathrm{Si} / \mathrm{Al}$ ratio and shape. Pure siliceous MFI type zeolite (silicalite-1) is not toxic, but the other three aluminium containing nanosized zeolites show a dose-dependent toxic manner.

The important factors considered for nanosized zeolites were particle size and crystalline morphologies. Recent work showed a definitive preference for cellular necrosis rather than programmed cell death via apoptotic mechanisms for the assayed conditions on particles with different sizes and morphology. ${ }^{174}$ The zeolites with and without functionalization showed different cytoxicity; the zeolites modified with amine were the most toxic. ${ }^{178}$

Further toxicity study of nanosized zeolites in different biological systems is needed. When considering potential application of biocompatible materials, their interaction with free radicals needs to be considered at an early exploratory stage. It is well known that free radicals play a key role in the human body, and therefore a convenient screening protocol was developed to identify the anti-oxidant and pro-oxidant properties of highly dispersed nanosized zeolites. It was found that TS-1 zeolite (Ti- containing MFI type zeolite) exhibits comparable or even better anti-oxidant activity in comparison to cerium oxide, while prooxidant activity was demonstrated for several other zeolites. ${ }^{178}$ A clear finding was that the toxicity of zeolites is dependent on the cell types used in the study. This implies that in vitro studies have to be carried out carefully using representative methodology.

The properties of crystalline MFI type nanosized zeolites (sizes of $50 \mathrm{~nm}$ and $100 \mathrm{~nm}$ ) and their toxicological effects on human lung alveolar (A549) cells under in vitro conditions were 
studied too. The biocompatibility of the nanoparticles by analysing their effect on the biological properties of cellular proliferation, cytotoxicity and both extracellular and intracellular free radical generation capacity was investigated. ${ }^{179}$ Live cell imaging showed that the nanoparticles precipitated from the colloidal suspension of cell culture media as large agglomerates, coming in contact with the cell surface through sedimentation. A cellular proliferative capacity test showed that the zeolite nanoparticles exhibit no cytotoxicity. DNA fragmentation analysis disclosed that the MFI nanosized zeolites cause genotoxicity in a concentration dependent manner. The conclusion drawn from this study showed that the pure silica MFI type nanosized zeolites were relatively non-reactive and cytotoxic to the human alveolar cells. The observed oxidative stress, heightened mitochondrial activity and genotoxic damages occur at environmentally non-relevant high dosage levels. Further studies are needed to provide a better understanding of the role of mitochondrial and other cell in causing oxidative stress and their possible relation with observed genotoxicity.

Another study reported on in vitro cytotoxicity test of nanosized zeolites with FAU and LTA type structures. ${ }^{173}$ For the cytotoxicological experiments human alveolar epithelial cells (A549), endothelial cells (EA.hy926) and differentiated monocytes (THP-1) were used. The cytotoxic response of macrophages, epithelial and endothelial cells to nanosized zeolites (sizes of 25-100 nm) was investigated, and no significant cytotoxic activity was detected for doses up to $500 \mu \mathrm{g} / \mathrm{mL}$ for $24 \mathrm{~h}$. More importantly, the nanosized zeolites showed lower toxicity in comparison to amorphous silica, which make them interesting for future applications in medicine and biochemical field. After exposure to $500 \mathrm{mg} / \mathrm{ml} \mathrm{nanosized}$ zeolites, up to $50 \%$ of the administered nanoparticle mass was found to be associated with the cells. However, only few nanosized zeolites were internalized in macrophage cells. There was no evidence for uptake in endothelial and epithelial cells. This suggested that the internal surface of microporous particles did not contribute to their biological activity.

Recently, we studied the toxicity of two types of ultra-small zeolites with LTL and EMT type structures synthesized from organic template free systems. ${ }^{180}$ Both the LTL and EMT type zeolites belong to the same group of molecular sieves; they have large pores ( $7.3 \AA$ ) and low silica content $(\mathrm{Si} / \mathrm{Al}=1.1-3.5)$. The cellular interactions with the two types of zeolite nanocrystals were evaluated by cell viability, reactive oxygen species and cell life cycleassays. It was found that various concentrations of zeolites have negligible effects on the cell life cycle. Moreover, the zeolites did not cause extensive oxidative stress on the cells. Although it is seen that the zeolites extensively entered in the cells, there is no sign of toxicity for all employed concentrations of ultra-small EMT and LTL zeolites. Additionally, no 
abnormality during the DNA replication by the zeolite exposure was observed. Very importantly, the EMT nanosized zeolite shows a high affinity for fibrinogen, moderate for apoA-II and complement factor 3, and trace affinity for albumin, which is the most abundant protein of human plasma. Thus the EMT nanosized zeolite can be considered as very promising material for purification of fibrinogen and lipoproteins, while keeping the highest concentration of albumin, when they are exposed to in vivo-like human plasma concentration. ${ }^{181}$ Fibrinogen is a very complex, hydrophilic and bipolar molecule. In contrary to fibrinogen, apolipoprotein C-III (APOC-III) is a simple, highly hydrophobic and non-polar molecule. The selective sorption behaviour of human plasma proteins on EMT and FAU nanosized zeolites with a size of $10 \mathrm{~nm}$ was presented. ${ }^{180,181}$ The protein composition of corona in EMT and FAU zeolite nanocrystals was strongly dependent on the plasma protein concentrations, zeolite external surface area and hydrophilicity, but it was independent of the concentration of zeolites used. In conclusion, the property of the EMT and FAU zeolite nanocrystals might be adapted to hemophilic patients (hemophilia A (F-VIII deficient) and hemophilia B (F-IX deficient) with a risk of bleeding.

The stability of natural zeolite (clinoptilolite) in simulated digestion conditions and their interactions with digestive media and with Caco-2 (human colon adenocarcinoma) cells was investigated. ${ }^{182}$ The cytotoxicity test using colon cancer cells showed that the natural clinoptilolite has cytotoxic effect against Caco-2 cells, and cytotoxicity did not significantly change with respect to simulated digestion process. ${ }^{182}$ Non-toxic nanosized zeolites with interesting physicochemical properties offer considerable advantages in everyday life uses as stated by Cola et al. ${ }^{183}$

In summary, most of the toxicity tests were performed on five types nanosized zeolites (LTA, MOR, LTL, FAU and MFI) (Table 1). The low cytotoxic activity of nanosized zeolites with different sizes, compositions and shapes are expected to enlarge their future industrial and medical applications. However, currently there are no standards for toxicological study of nanosized zeolites. Therefore, the safety analysis of zeolites with different structures, morphology, size and chemical compositions is of highest priority given the expected worldwide use and the probability of exposure to human being. 
Table 1. Toxicity of nanosized zeolites.

\begin{tabular}{|l|l|l|}
\hline Zeolite & Toxicity & Cell \\
\hline $\begin{array}{l}\text { LTA, MFI } \\
\text { (ZSM-5, } \\
\text { silicalite-1); } \\
\text { LTL }\end{array}$ & $\begin{array}{l}\text { Pure silica zeolites are not } \\
\text { toxic. Aluminum-containing } \\
\text { nanosized zeolites show a } \\
\text { dose-dependent toxic manner. }\end{array}$ & $\begin{array}{l}\text { Human embryonic kidney 293 (HEK- } \\
\text { 293); RAW264.7 macrophage; HeLa } \\
\text { cells. }\end{array}$ \\
\hline $\begin{array}{l}\text { LTA, FAU, } \\
\text { MFI }\end{array}$ & $\begin{array}{l}\text { Non-cytotoxic zeolite } \\
\text { nanoparticles. }\end{array}$ & $\begin{array}{l}\text { Lung alveolar (A549) cells; } \\
\text { Endothelial cells (EA.hy926); } \\
\text { Differentiated monocytes (THP-1). }\end{array}$ \\
\hline EMT, LTL & $\begin{array}{l}\text { Non-toxic with affinity for } \\
\text { fibrinogen and apoA-II. No } \\
\text { affinity for albumin. }\end{array}$ & $\begin{array}{l}\text { HeLa cells. Cell viability, reactive } \\
\text { oxygen species. }\end{array}$ \\
\hline Clinoptilolite & $\begin{array}{l}\text { Non-toxic zeolite. } \\
\text { Colon adenocarcinoma cancer cells } \\
\text { (Caco-2). }\end{array}$ \\
\hline
\end{tabular}

\section{Antibacterial applications of nanosized zeolites}

Antibacterial inorganic materials present important advantages over traditionally used organic agents. The inorganic materials offer the advantage of chemical and thermal stability and thus flexible processing during preparation of nanocomposites, alloys, coatings and other complex structures. ${ }^{184}$ Amongst them, the silver in different forms, with its broad spectrum of antimicrobial properties, has become one of the most intensively studied. There have been certain degrees of controversy in mechanistic studies of silver toxicity because of the huge variations in antibacterial tests and type of silver systems used. ${ }^{185}$ The anti-bactericidal effect of silver nanoparticles dependent on their size, as the silver nanoparticles with sizes below $10 \mathrm{~nm}$ were found to directly interact with bacterial cells. Further, it has been demonstrated that activity of silver nanoparticles was due to the aerobic release of silver ions and silver metals $\left(\mathrm{Ag}^{0}\right) \mathrm{did}$ not have any bactericidal properties. ${ }^{186}$ Therefore, in order to insure long-term antibacterial applications, silver was incorporated into media, such as zeolites. By increasing the Ag loading in zeolites an increased antimicrobial activity was observed. ${ }^{187}$ Inoue and co-workers reported on the antibacterial activity of silver 
loaded FAU type zeolite against Escherichia coli (E. coli), thus showing an increase in bacterial susceptibility in the case of rifampicin. ${ }^{188}$

The stabilisation of Ag within the zeolite matrix resulted in enhanced antifungal activity in comparison with free Ag ions. ${ }^{189,190}$ The antibacterial properties of Ag loaded zeolites were found to depend on various factors such as the physical form of the zeolite host (e.g., powder, granules or pellets), the zeolite framework, and the silver form either cations $\left(\mathrm{Ag}^{+}\right)$or metal nanoparticles $\left(\mathrm{Ag}^{0}\right) .{ }^{191}$ The antibacterial properties of nanosized EMT zeolite with $\mathrm{Ag}^{+}$and $\mathrm{Ag}^{0}$ stabilized in aqueous suspensions were reported recently from our group. The EMT type zeolites with high silver content have shown excellent antimicrobial activity against $E$. coli (Figure 11). ${ }^{191}$ The results demonstrated that $E$. coli cells are instantly killed upon exposure to water suspensions of ultra-small $\mathrm{Ag}^{+}$-EMT and $\mathrm{Ag}^{0}$-EMT zeolites. However, the differences are not substantial and the preparation of $\mathrm{Ag}$ nanoparticles $\left(\mathrm{Ag}^{0}\right)$ instead of using $\mathrm{Ag}$ cations $\left(\mathrm{Ag}^{+}\right)$was not advantageous considering the complexity of preparation steps. ${ }^{191}$ In the presence of Ag-EMT samples with different Ag loading, the number of viable E. coli cells visually decreased over time and no viable cells were detected after 1 and 2 minutes of incubation (Figure 11, left). For the EMT samples containing $\mathrm{Ag}^{0}$, no viable E. coli was seen (Figure 11, right).

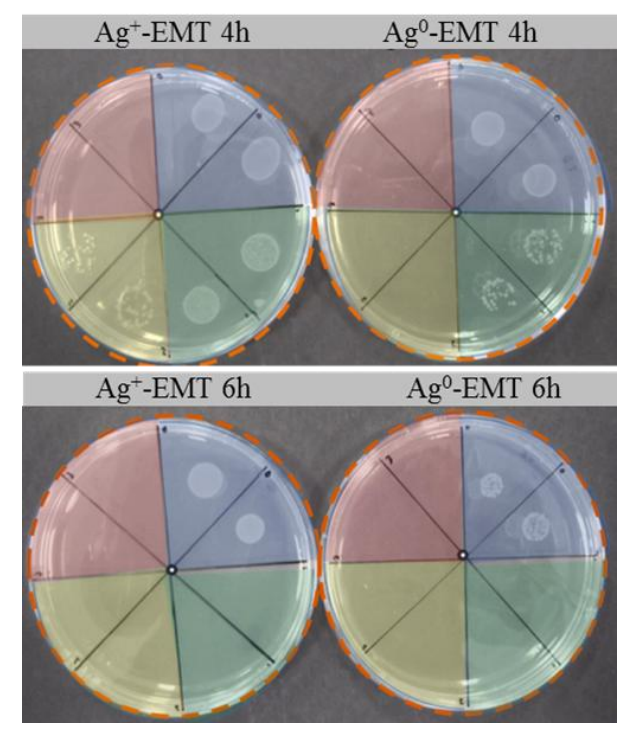

Figure 11. Spot inoculation of E. coli onto thioglycollate agar plates (in duplicate) following 1-minute interval exposure to $\mathrm{Ag}^{+}$-EMT and $\mathrm{Ag}^{0}$-EMT nanosized zeolite samples. Each drawn slice above corresponds to one minute sampling time; the first sample is taken directly after mixing ( 0 min). 
The effect of silver-exchanged mordenite (MOR) against the growth of six fungi (Rhizopus oryzae, Mucor circinelloides, Geotrichum candidum, Saccharomyces cerevisiae, Debaryomyces hansenii and Zygosaccharomyces rouxii) was studied. ${ }^{192}$ It was shown that the Ag released from the Ag-mordenite have effective antifungal action and being more effective than the free silver ions in solutions. Interestingly, the Geotrichum candidum was the more resistant, while the yeasts were more sensitive than filamentous fungi.

The antibacterial activity of cutting boards containing silver-based layers was studied too. ${ }^{193}$ The humidity was found to have noticeable effect on bacteria killing (staphylococci, Escherichia coli, Salmonella, Serratia and Listeria monocytogenes). If no substantial water content was present during the use, then the antibacterial activity of the silver was negligible. Additionally, patterned-zeolite films consisting of FAU zeolite crystals were also found to be efficient towards eradication of E. coli. ${ }^{194}$ Another example is a nitrogen oxide (NO) loaded Zn-containing zeolite, which was also, used as bi-functional anti-bacterial material. ${ }^{195}$

In summary, the nanosized zeolites would be very advantageous for antibacterial applications having in mind that they can be deliver in different stable forms such as (i) suspensions, (ii) discrete solid particles, (iii) deposited in films and membranes, and (iii) self-supported bodies (diverse sizes and shapes) with very high external surfaces and great accessibility. Thus the efficiency of the nanosized zeolites as antibacterial carrier is expected to be higher than their micronsized equivalents.

\section{Drug delivery application of nanosized zeolites}

The immobilization of biomolecules on the surface of porous nanocrystals (zeolites and mesoporous silica) is the focus of intense activity in biotechnology and biomedicine. Especially, amine groups in proteins can be bound to the surface of zeolite particles and stabilized electrostatically. In addition, nanosized zeolites show great promise as substrates to immobilize proteins due to their small size and high functional groups density for further grafting. The hydrophilic/hydrophobic nature, high stability and high sorption capacity of nanosized zeolites make them important for further application in pharmaceutical industry and medicine.

Drugs or contrasting agents can be confined within the pores or cages of zeolites. There are cases where the drug of interest is attached to the external surfaces, and therefore the interest is in the synthesis of zeolites with high external surface area. Examples of using nanosized zeolites as multifunctional nanocarriers to deliver organic molecules into living cells were 
presented. ${ }^{196}$ Both the surface and the internal pore volume of the LTL nanosized zeolite were used after post synthesis functionalization, and the release of a drug molecule (4', 6diamidino-2-phenylindole, DAPI) from the zeolite pores was demonstrated. ${ }^{196}$

The application of nanosized zeolites for biomedical applications, controlled carry and delivery of probes are envisioned for theranostic and gene therapy applications too. ${ }^{197-204} \mathrm{New}$ horizons in clinical medicine have been opened using nanosized zeolites, in particular the multifunctional therapeutic delivery systems. ${ }^{205}$ Mostly, LTL type zeolite was applied as drug carrier, and a great promise for immobilization of proteins due to their small size, sufficient functional groups, surface hydrophilic/hydrophobic distribution and stable colloidal properties was shown. The LTL nanosized zeolite were used as a trypsin-immobilizing carrier and patterned in a poly(Me methacrylate) (PMMA) microfluidic channel for the fabrication of enzyme microreactor. Due to the high trypsin immobilization capacity and unique surface characteristics of LTL nanosized zeolite, the resulting trypsin microreactor had the efficient digestion of proteins at low concentrations for a very short reaction time. ${ }^{206}$

On the other hand, zeolites have been investigated for encapsulation of drugs in their cavities not only in the channels like in the case of the LTL nanosized zeolite. The ability of storing and releasing of a variety of drugs in the FAU type zeolite was reported. ${ }^{207-209}$ The FAU zeolite demonstrated a slow release for various anthelmintic drugs. ${ }^{210}$ FAU type zeolite was used as a slow-release carrier for some anthelmintic drugs. Besides, doxorubicin and paraquat molecules have been successfully loaded in the FAU zeolite functionalized with a trimethylsilyl. The controlled release of sulfonamide antibiotics adsorbed on the FAU type zeolite was investigated by changing the pore mouth opening, modifying the external surface, and the nature of the grafted functional groups. ${ }^{201}$ The controlled release of ibuprofen encapsulated in de-aluminated FAU zeolite was another example of an efficient drug delivery. ${ }^{211,212}$

As indicated before, the nanosized zeolites possess both the micropores and textural mesopores that are potentially large enough to accommodate a wide-range of different drug molecules, such as sulfonamide antibiotics, ibuprofen, doxorubicin, mitoxantrone, aspirin and 5-Fluorouracil (5-FU). ${ }^{202,213-216}$ The ibuprofen immobilized in the FAU zeolite showed better release behaviour than the observed for mesoporous silica (MCM-41 type material).

Therapy with classical drugs (5-FU) has often-toxic side effects. Thus, the encapsulation of 5FU in zeolites may contribute to reduce these side effects and may allow an oral administration as well. Encapsulation may allow drugs to be released in a controlled way to the cancer area, thus preventing toxicity. The anticancer drug (5-FU) was encapsulated in 
FAU and LTL zeolites. ${ }^{217}$ In vitro drug study revealed the release of $80-90 \%$ of 5-FU in the first $10 \mathrm{~min}$. The drug delivery system (DDS) was also evaluated using two human colorectal carcinoma cell lines (HCT-15 and RKO). Unloaded zeolites presented no toxicity to both cancer cells, while all DDS showed an important 5-FU effect on the cell viability. DDS based on zeolites were able to increase the efficiency of 5-FU, a widely used anticancer drug. ${ }^{217}$ These systems should be further explored in other cancer models, e.g. in vivo models, to confirm their efficiency. The same group reported on the preparation of zeolite with anticancer drug cyano-4-hydroxycinnamic acid (CHC) and demonstrated its efficacy against colorectal carcinoma cells. ${ }^{204,218}$ The anticancer drugs were loaded into the pores of zeolite $\mathrm{Y}$ (FAU), zeolite A (LTA) and zeolite Beta (BEA), and they have shown a noticeable cytotoxic effect when applied to cancer cells. ${ }^{204,219}$ However, the zeolites alone reveal no toxicity to cancer cells, while, importantly, anticancer drug-zeolite led to an inhibition of cell viability up to 585-fold when compared to the non-encapsulated drug.

Larsen and co-workers investigated the loading and release of Aspirin and 5-FU from the FAU type zeolite with different $\mathrm{SiO}_{2} / \mathrm{Al}_{2} \mathrm{O}_{3}$ ratios of 5, 30, and $60 .{ }^{215}$ They found that the aluminum content in the zeolite plays a critical role in determining the drug loading and release profiles. Aspirin and 5-fluorouracil loadings were found to increase with increasing aluminum content in the FAU zeolite crystals. In this release system, the aluminum has an integral role in governing the interactions between zeolite crystals and drug molecules. The zeolite with the highest aluminum content may interact with the drug molecule species by hydrogen bonding of the carbonyl oxygen atoms with the zeolite hydroxyl groups as well through coordination of the drug molecules to the aluminum atoms. ${ }^{215}$ Aspirin was bonded to silanol sites via hydrogen bonding on FAU zeolite with higher $\mathrm{SiO}_{2} / \mathrm{Al}_{2} \mathrm{O}_{3}$ ratio. The drug release study from the zeolite matrix at neutral $(\mathrm{pH}=7.4)$ in aqueous media revealed nearly complete release of the aspirin from the FAU zeolite with high alumina loading, while partial release of the aspirin for high silica FAU zeolite was observed. The partial release of the drug was attributed to the increased hydrophobicity of the materials due to an increase of van der Waals interactions. The nature of intermolecular aspirin-zeolite interactions was studied in detail by spectroscopic methods. ${ }^{218,220}$

Zeolites X (FAU type) and A (LTA type) were used for encapsulation and controlled release of Ketoprofen drugs. ${ }^{213}$ The ketoprofen was encapsulated in the zeolite matrix by a soaking procedure, and it was shown that no drug release in acid conditions is observed, thus suggesting that the material has great potential for controlled delivery of ketoprofen. ${ }^{213}$ Immobilization of famotidine (sulphonamide derivative) on two zeolite structures (MFI and 
MOR) revealed that the amount of famotidine adsorbed was generally greater in ionexchanged-zeolites, suggesting that these cations act as binding sites for the famotidine molecules. The equilibrium and kinetic characteristics of the drug on these materials were studied by varying the incubation time, the famotidine concentration and the $\mathrm{pH}$ of the solution. ${ }^{221}$ Zeolite crystals modified with polyaniline were prepared and used for controlled release of an antibiotic (cefuroxime). The zeolite doped with the antibiotic showed longer time for cefuroxime discharge, and about $42 \%$ remained in the zeolite after 6 h. ${ }^{222}$

Natural enzymes frequently suffer limitations in various applications due to denaturation. They are easily deactivated under extreme temperatures and/or $\mathrm{pH}$. For these reasons, zeolites were also used as drug carriers and delivery systems for a number of enzymes such as glucose oxidase and antibodies. $^{223,224}$

Exploring the possibility of using zeolites in tissue engineering scaffolds is a potential approach in regenerative medicine because of their biocompatibility and cation exchange ability. ${ }^{225}$ A novel method to synthesize formaldehyde cross-linked gelatine/zeolite scaffolds by lyophilisation technique was reported. Swelling and degradation of scaffolds were tuned by adjusting the concentrations of zeolites in the composite scaffolds. All these results suggest that they can be further investigated for their application in tissue engineering.

The preparation of novel zeolite-hydroxyapatite composite coating on titanium alloys and stainless steel for regenerative medicine was presented recently. ${ }^{226}$ The zeolite-hydroxyapatite coating is super-hydrophilic and outperforms in corrosion resistance tests in aggressive sodium chloride media and phosphate buffer solution. Moreover, the zeolite coating eliminated the elastic modulus mismatch between the coating and the bone. In addition, it was observed faster post-surgical recovery.

\section{Medical imaging based on nanosized zeolites}

Nanosized zeolites modified with folic acid are recognized for application in targeting treatment of damaged cells. Manufacturing of such multifunctional systems in a way to carry bioactive molecules, able to recognize specific targets in living cells, represents an achievement towards the development of highly selective tools for both diagnosis and therapeutics. A review summarizing the applications of zeolites nanocrystals for immobilization of enzymes and their use in magnetic resonance imaging was published. ${ }^{227}$ The materials possessing unique properties that enable radionuclides and contrast agent metals to be concentrated and thus to be more efficient in magnetic resonance imaging (MRI) and nuclear medicine were identified. ${ }^{228}$ The possible application of zeolites in positron 
emission tomography (PET) was also studied. The ion-exchange capabilities of FAU type zeolites make it an ideal vehicle for ionic metal MRI contrast agents including $\mathrm{Gd}^{3+}$ and positron-emitting radionuclides $\left({ }^{68} \mathrm{Ga}^{3+}\right)$. Besides, the zeolite crystals were subjected to surface modification via trialkoxysilane condensation, which add biological selective moieties to the zeolite surface, and led to the concentration of the crystals at specific locations in the body.

Zeolites functionalized with molecular targeting vectors (e.g., peptides, aptamers) that enable specific high-affinity binding to in vivo molecular targets (such as cell surface receptors) were investigated. In addition, these materials possess unique properties that enable radionuclides and contrast agent metals to be concentrated for applications in magnetic resonance imaging (MRI) and positron emission tomography (PET). Some luminescent molecules such as iridium (Ir) and europium (Eu) complexes and organic dye in LTL nanosized zeolite were introduced and used for biology imaging. ${ }^{198,229,230}$ The light responsive components in combination with the small zeolites (diameter of $30 \mathrm{~nm}$ ) have been very successfully prepared. The LTL nanosized zeolites were loaded with an emitter, and the surface was functionalized with a phthalocyanine derivative and amino groups, thus non-covalent binding of the hybrid nanomaterial to the bacterial surface was achieved. The results demonstrated that hybrid nanomaterials efficiently produced singlet oxygen and adhered to bacterial surfaces, leading to targeting, labelling, and photoinactivation capabilities against antibiotic-resistant bacteria.

Additionally, iron oxide nanoparticles feature in vivo applications including magnetic resonance, imaging contrast enhancement, tissue repair, drug delivery and treatment of hypothermia. Pure silica (silicalite-1) nanosized crystals containing magnetite were prepared and the sorption of hemoglobin $(178 \mathrm{mg})$ at neutral $\mathrm{pH} 7$ was studied. ${ }^{231}$ The possibility of combining the properties of the zeolite with the magnetite super paramagnetic nanoparticles was demonstrated.

Vectorized therapies for tumours based on inorganic nanomaterials have recently been proposed to be an exciting approach. The nanoparticles with vectorezation properties were used to deliver different drugs in tumours. ${ }^{232}$ The advances in the design of nanoscale stimuliresponsive systems able to control (i) drug bio-distribution under variation of temperature, and (ii) in the presence of magnetic field, ultrasound, light or electric pulses, or (iii) under changes of the $\mathrm{pH}$, enzyme concentration or redox gradients, were described. ${ }^{233}$ Additionally they were used for synchronized MRI and focused-ultrasound enhanced brain-tumour drug delivery. 
Gas storage in nanosized zeolites for medical applications

Another applications for nanosized zeolites include storage and controlled delivery of gases in biological systems. Reversible adsorption is a good method of storing a desire gas in a material from which a controlled delivery is required. The application of oxygen concentrators for the supply of medical oxygen in remote places has important cost saving and supply implications. The zeolite trapped nitrogen from compressed room air, and thus concentrates the oxygen in the expressed gas. At delivery flow rates of 2 to 51 per minute, oxygen concentrations greater than $80 \%$ was maintained. ${ }^{234}$ The possibility of using zeolites for oxygen concentrator was demonstrated for packed LTA zeolite, which produces humidified $\mathrm{O}_{2}$-enriched air because $\mathrm{H}_{2} \mathrm{O}$ is adsorbed and recovered together with the oxygen. Oxygen concentrators for the delivery of supplemental oxygen in remote highaltitude areas were constructed using LTL zeolite. ${ }^{234}$ Another paper reports on the use of both 5A (Ca-LTA-type) and partially Ag- and Li-exchanged 13X (FAU- type) zeolites, wherein the oxygen purity was greater than $90 \%$. The zeolite carriers for oxygen with reduced size are interesting for personal and medical applications. ${ }^{235}$ Besides, the efficient oxygen supply is a continuing challenge for the fabrication of successful tissue engineered constructs. Therefore an effort to enhance oxygen delivery via using fluorinated zeolite particles embedded in threedimensional polyurethane scaffolds was exploited. ${ }^{236}$ The concentration of oxygen substantially increased via treatment of the zeolite with $1 \mathrm{H}, 1 \mathrm{H}, 2 \mathrm{H}, 2 \mathrm{H}-$ perfluorodecyltriethoxysilane. The fluorinated-zeolite particles embedded in 3-D tissue engineered polyurethane scaffolds had high homogeneity. It was shown that polyurethane scaffolds with zeolites could be used for tissue engineering with enhanced oxygen delivery to the cells. Artificial mechanical red blood cells (respirocytes) mimic the oxygen and the carbon dioxide function as transport of red blood cells. They can deliver more than 200 times oxygen per unit volume than a natural red blood cell. ${ }^{237}$

The tuneable nature of NO release from ion exchanged LTA zeolites extends their potential applications to tubing and instruments used in procedures such as bypass surgery and renal replacement therapy. ${ }^{238}$ As specific potential, the use for NO-releasing zeolite in the cardiovascular arena centers on the prevention of thrombosis on artificial surfaces coming in contact with blood was considered. Additionally the zeolite loaded with NO was studied for application in catheter implantations, and stents. It was demonstrated that between different ion exchanged zeolites, the Co-containing LTA zeolite has the highest affinity for NO even at low pressure. The amount of NO released from the zeolite in water solution was measured electrochemically and between the numerous samples, the Co-exchanged zeolites released the 
most NO while the Na-LTA zeolite released least NO. It was shown that the amount of NO released by the zeolite was dependent not only on the type of transition metals but also on the amount and state of the metal present. In conclusion, the loading with NO in the zeolite was simple and the release occurred by a reaction with water. Besides, the NO releasing zeolites inhibit platelet aggregation and adhesion in plasma, which is of potential importance in prevention of thrombus formation. The application of NO-release zeolites will extend far beyond the confines of reduced thrombogenicity of prosthetic grafts, catheters, and extracorporeal blood conduits. Other medical uses including antimicrobial adjuncts to prevent infection, for example, in chronically implanted catheters and in wound dressings for enhanced angiogenesis were considered from the same group.

Typically applied nitric oxide induces T-Lymphocyte infiltration in human skin, but minimal inflammation. ${ }^{239}$ Nanoparticles of natural zeolite (clinoptilolite) were applied on textiles as protective finishes material. The nanosized zeolite crystals with increased active surface area scatter the light and thus provide a textile with a high level UV protection.

The main biological and medical applications for zeolites are summarised in Table 2.

Table 2. Drugs and gases loaded in zeolites for biological systems and medical applications.

\begin{tabular}{|c|c|c|}
\hline Zeolite & Drug & Application \\
\hline LTL & $\begin{array}{l}\text { 4',6-diamidino-2- } \\
\text { phenylindole }\end{array}$ & Multifunctional therapeutic delivery systems. \\
\hline LTL & Trypsin & Enzyme microreactor. \\
\hline FAU & Anthelmintic compounds & Slow release carrier. \\
\hline FAU & $\begin{array}{l}\text { Doxorubicin, Paraquat } \\
\text { molecules, Antibiotics, } \\
\text { Sulfonamide, Ibuprofen, } \\
\text { Mitoxantrone, Aspirin, } \\
\text { 5-Fluorouracil }\end{array}$ & Efficient drug loading. Controlled release. \\
\hline $\begin{array}{l}\text { LTA, } \\
\text { FAU }\end{array}$ & Ketoprofen & $\begin{array}{l}\text { Controlled and selective delivery (no release in } \\
\text { acidic media). }\end{array}$ \\
\hline $\begin{array}{l}\text { LTA, } \\
\text { FAU, } \\
\text { BEA }\end{array}$ & $\begin{array}{l}\text { Anticancer drug, Cyano-4- } \\
\text { hydroxycinnamic acid, } \\
\text { 5-Fluorouracil }\end{array}$ & $\begin{array}{l}\text { Inhibition of cell viability. High efficiency to } \\
\text { colorectal carcinoma cells. }\end{array}$ \\
\hline
\end{tabular}




\begin{tabular}{|l|l|l|}
\hline $\begin{array}{l}\text { MFI, } \\
\text { MOR }\end{array}$ & $\begin{array}{l}\text { Famotidine (sulphonamide } \\
\text { derivative), Cefuroxime }\end{array}$ & $\begin{array}{l}\text { High loading dependent on } \mathrm{pH} \text { and zeolite/drug } \\
\text { concentrations. }\end{array}$ \\
\hline FAU & $\begin{array}{l}\text { Natural enzymes, Glucose } \\
\text { oxidase, Antibodies }\end{array}$ & Stabilization at various $\mathrm{pH}$ and temperatures. \\
\hline $\begin{array}{l}\text { LTA, } \\
\text { Co-LTA }\end{array}$ & $\mathrm{O}_{2}, \mathrm{CO}_{2}, \mathrm{NO}$ & $\begin{array}{l}\text { Storage and controlled delivery of gases. } \\
\text { Treatment of cardiovascular centers. Prevention } \\
\text { of thrombosis on artificial surfaces. } \\
\text { Antimicrobial adjuncts for prevention of } \\
\text { infections. }\end{array}$ \\
\hline
\end{tabular}

\subsubsection{Nanosized zeolites in cosmetics and food}

The nanosized zeolites are very attractive and can be safely applied in processes to (1) absorb unpleasant odours, (2) for skin cleaning, (3) protect from harmful emissions, microorganisms and rheumatic problems, (4) speed the healing of skin wounds and (5) regulate the alkalinity. Zeolite crystals containing di- and poly- valent metal cations were used for delivery of important biological compounds to skin and hair care agents. Additionally, delivery of certain metals, including trace metals, and certain zirconium aluminum amino acids that provide antiperspirant benefits were introduced in the cosmetic compounds. ${ }^{240}$ Another application is based on ion exchange zeolites mainly with $\mathrm{Cu}$ and $\mathrm{Zn}$ as fillers in cosmetics. This cosmetic has curative-and-prophylactic anti-inflammatory effect on facial skin. Besides, the cosmetics with zeolite fillers were used to remove toxins and to decrease greasiness and to deliver necessary micro- and macro-elements and to regenerate the skin. ${ }^{241}$ Another trends are in the preparation of self-heating cosmetic compositions containing zeolites. ${ }^{242,243}$ The zeolites were loaded with hydrocarbon oil, caprylic triglyceride, cyclomethicone, and ethanol. During the application of the zeolite, the skin maintains warm and increases softness and reduces dryness. In most cases, non-aqua exothermic cosmetics containing LTA type zeolites was used, which effectively eliminates impurities on skin and promotes blood circulation during the exothermal process of treatment. This cosmetic was applied to skin and hair, where the temperature was increased of $16{ }^{\circ} \mathrm{C}$ for 1 min under mixing with water. The cosmetics were loaded with 25 wt.\% zeolites and dimethylsiloxane-methyl(polyoxyethylenepolyoxypropylene)siloxane copolymer. These exothermic cosmetics contained ethoxylate alcohols $\left(\mathrm{C}_{5-25}\right)$ and hydrophilic non-aqua solvents including glycerine, propylene glycol and 1,3-butylene glycol. The exothermic cosmetic based on zeolites was prepared in the form of creams, lotions, gels, packs, pastes and deodorant sticks. Besides, it was found that the self- 
heated cosmetic was very efficient for massage and face cleansing. Modified LTA zeolite with polyethylene glycol, 1,3-butylene glycol, glycerine, $\mathrm{Ca}(\mathrm{OH})_{2}, \mathrm{H}_{3} \mathrm{PO}_{4}$, and surfactants was used. The LTA type zeolite was modified with magnesium or calcium halide as well. The halides were used to adjust the $\mathrm{pH}$ of the cosmetics at a value suitable for the skin. Cosmetic compounds containing zeolites were applied as cleansing creams, hand cleaner, hand lotions, cream shampoo and toothpaste compounds too. ${ }^{244}$

Metal-exchanged zeolites (copper, silver) exhibit good antibacterial activity for both gram-negative and gram-positive bacteria, and this effect was developed in a short period of time. A new antifungal material, Ag-zeolite, was combined with a commercial tissue conditioner as a successful agent against Candida albicans growth and acid production. The inhibitory effects of these materials on fungal growth were decreased by the presence of a saliva coat, particularly with zeolite in a tissue conditioner.-A silver zeolite mouth rinse was prepared by suspending zeolite powder into phosphate-buffered saline at a concentration of 3 wt. $\%$.

In addition to the use of zeolites in cosmetics and household items, they were applied in the beer industry as energy supply. ${ }^{245}$ The concept for heat supplying is based on water adsorption heat within zeolites.

The zeolites were also used as ingredients in packing materials for food. ${ }^{246}$ The metal (silver, zinc, copper) containing zeolites were incorporated into food contact polymers to enhance their mechanical strength and to prevent the degradation of plastics. Besides, the silver containing zeolites worked as effective antimicrobial compounds, decrease ethylene oxidation play the role of oxygen scavenger, thus increase the lifetime of food.

Zeolite nanocrystals were used as selective adsorbents for palm oil purification. ${ }^{24,248}$ The zeolites with electrostatic charged framework tend to allow polar compounds such as moisture contaminant and carbonyl oxidized products to be adsorbed and trapped in their pores, while do not interact with the non-polar oil molecules. Recently, the use of zeolite nanocrystals as eco-friendly anti-oxidant additives was reported. ${ }^{249}$ Zeolite nanocrystals with different framework structures (LTL, EMT and FAU) were found to possess distinctive anti-oxidation behaviour in palm oil during heat treatment $\left(180{ }^{\circ} \mathrm{C}\right)$ for a long period of time (40 days). It was shown that the delay of palm oil oxidation is the result of free radicals inactivation, $\mathrm{C}=\mathrm{C}$ bonds stabilization and also adsorption of polar primary (hydroperoxides) and secondary (carboxylic acids) oxidation products by zeolites. The FAU nanosized zeolite prepared from template-free precursor suspensions in different ion exchange forms $(\mathrm{Li}, \mathrm{Na}, \mathrm{K}$, and $\mathrm{Ca}$ ) were used as additives in palm oil (Figure 12). It was clearly shown that only $1 \%$ zeolite 
nanocrystals added to the palm oil increased the lifetime with $47 \%$. For real application, the nanosized zeolites will be incorporated in membranes or deposited as thin film on the culinary tools for deep-frying, apart than been added directly into the cooking oil.

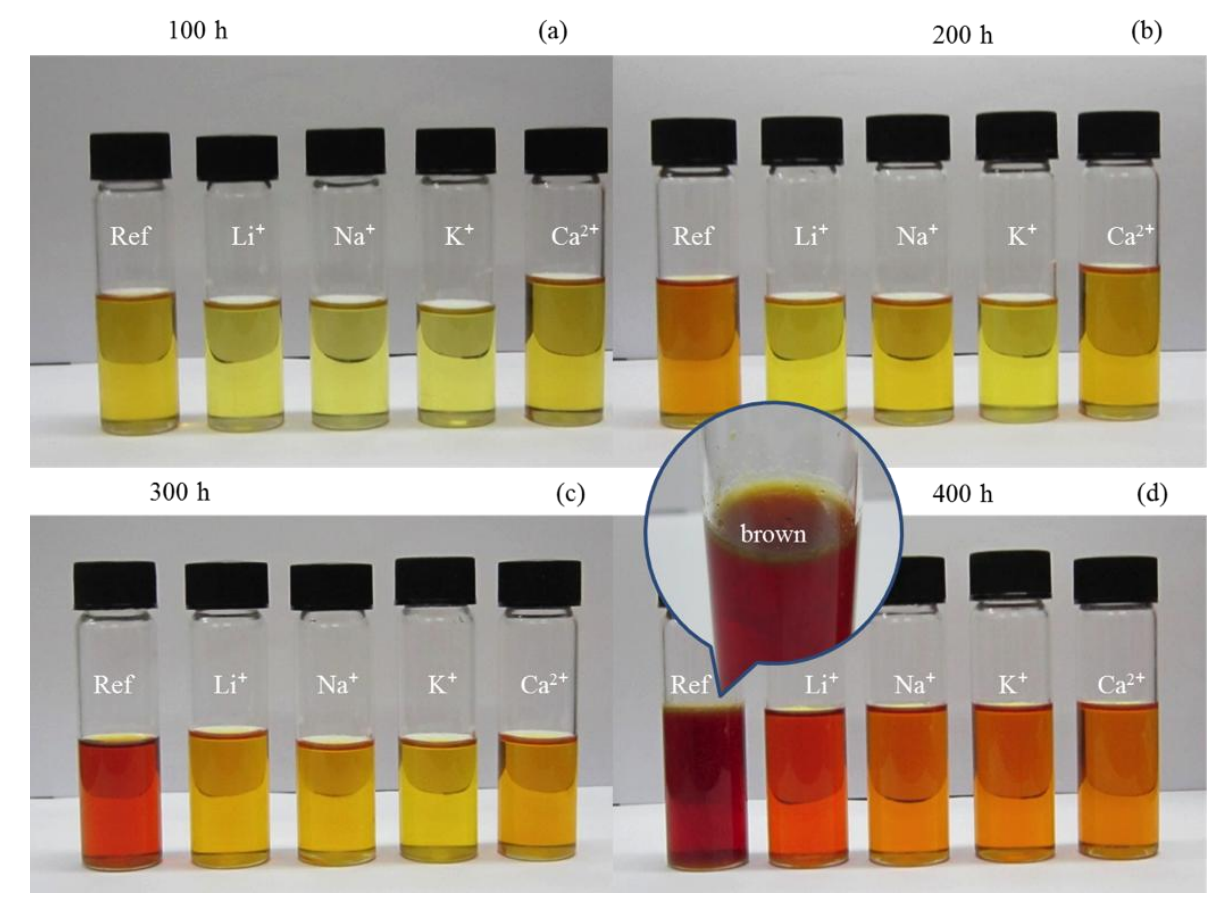

Figure 12. Anti-oxidation behaviour of ion exchange nanosized FAU zeolites ( $\mathrm{Li}, \mathrm{Na}, \mathrm{K}$, and Ca) added to palm oil during heat treatment at $180{ }^{\circ} \mathrm{C}$ for $100,200,300$ and $400 \mathrm{~h}$. (Ref: the reference sample is oil oxidized without zeolite.)

The zeolites used in cosmetics and food productions with the corresponding functions are presented in Table 3.

Table 3 Applications of nanosized zeolites in cosmetics and food.

\begin{tabular}{|l|l|}
\hline Zeolite & Function \\
\hline LTA, FAU & $\begin{array}{l}\text { Metal amino acids in zeolites with antiperspirant effect in cosmetic } \\
\text { compounds. Zeolites loaded with alcohols promote skin blood } \\
\text { circulation. }\end{array}$ \\
\hline $\begin{array}{l}\text { Zn-, Cu- LTA, } \\
\text { FAU }\end{array}$ & $\begin{array}{l}\text { Prophylactic anti-inflammatory effect. Remove toxins. Decrease } \\
\text { greasiness of skin. Deliver necessary micro- and macro-elements and } \\
\text { regenerate skin. }\end{array}$ \\
\hline
\end{tabular}




\begin{tabular}{|l|l|}
\hline LTA, FAU & $\begin{array}{l}\text { Adjust the pH of skin. Delivery of Ca and Mg in cleansing creams, hand } \\
\text { lotion, cream shampoo, and toothpaste. }\end{array}$ \\
\hline LTA & Self-heating cosmetics based on spontaneous adsorption of water. \\
\hline Cu-, Ag-LTA & $\begin{array}{l}\text { Antibacterial activity. Antifungal effect. Anti-stimulus of acidic } \\
\text { compounds. Mouths rinse with phosphate-buffered saline antibacterial } \\
\text { zeolite suspensions. Denture plaque control. }\end{array}$ \\
\hline LTA, FAU & $\begin{array}{l}\text { Mechanical strength enhancement of food packing materials. Prevent } \\
\text { degradation of plastics packing materials. Oxygen scavenger for } \\
\text { increase of food lifetime. }\end{array}$ \\
\hline EMT, FAU, & $\begin{array}{l}\text { Anti-oxidant effect in oil. Purification of oxidized oil. Increase of } \\
\text { lifetime of vegetable cooking oil. }\end{array}$ \\
\hline
\end{tabular}

\subsection{Applications of nanoclays}

Nanoclays have been known and used by humans since antiquity. These materials have been employed in ceramics, porcelain, bricks, tiles, as well as an essential constituent of plastics, paints, paper, rubber, and cosmetics.

Nanoclays are widely used in pharmaceutical domains both as excipients and active agents. ${ }^{250}$ The most known example of the use of nanoclay in the drug delivery system is the intercalation of ibuprofen. Donepezil, a well-known drug for Alzheimer's disease, was also reported to be intercalated in several smectites including laponite. ${ }^{250,251}$ Nanoclay minerals for instance the Halloysite $\left(\mathrm{Al}_{2} \mathrm{Si}_{2} \mathrm{O}_{5}(\mathrm{OH})_{4} \cdot \mathrm{H}_{2} \mathrm{O}\right)$, which is a two layered (1:1) tubule aluminosilicate with multilayer walls has been used for release of drugs and other chemical agents. This nanoclay is also used in the preparation of bone implant poly(methyl methacrylate) nanocomposites. ${ }^{252,253}$

Organonanoclays can also usefully serve as carriers and delivery systems for the controlled release of drugs. ${ }^{254,255}$ Several studies have demonstrated the applicability of clays to stimulate the osteogenic induction of responsive cells via direct clay interactions. For example, the response of a pre-osteoblast cell line to osteogenic induction has been investigated as a function of Laponite content in PEO nanocomposite film surfaces. ${ }^{256,257}$ Laponite, the most representative example of nanoclay is used in many applications such as household products including cosmetics and toothpaste, surface coatings, agricultural and horticultural applications, ceramics, enamels, oil field applications, organoclay nanocomposites, etc. Depending on its great thickening property, Laponite can be used as in 
dentifrices for hypersensitive teeth. ${ }^{258}$ It can also be used to prepare multifunctional particulate additives for personal care and cosmetic compositions. Laponite can function as a binder either alone or with an additional binder component for catalysis with improved performance. ${ }^{87}$ Besides, Laponites is used to prepare light weight rubber and absorbent articles for sequestering skin irritants ${ }^{259}$, for oxygen gas barriers alone or in composite with grapheme. $^{260-262}$

Anticorrosion applications were also investigated. Confinement of benzotriazole into Halloysite improves the anticorrosion performance. ${ }^{263}$

Nanoclays are reported to be excellent candidates for remediation by adsorption of different inorganic and organic pollutants including dyes, heavy metal cations, pesticides and volatile organic compounds. ${ }^{264}$

But still the most important applications of nanoclays are as fillers for polymers. A number of review papers as well as several books entirely devoted to the subject have appeared. ${ }^{265-272}$ The first reason to add nanoclay fillers to polymers was to reduce costs. But it later turned out that a small amount of clay added as a filler could bring additional benefits, as witnessed by the synthesis of nylon 6-clay hybridthat has been commercialized by Toyota in Japan. ${ }^{273}$ In fact, in other domains it was already known that their small size, and large crystal aspect ratio allow clay minerals to strongly influence the physical properties of soils and sediments.

Recently, composites based on nacres and nanoclays were prepared. Besides a full transparency, glass-like nacre-mimetics for the smaller aspect ratio nanoclays, showed the best gas barrier properties known for nacre-mimetics. ${ }^{274,275}$ Nanocomposites based on Montmorillonite and green algae have been reported to have a beneficial effect on animal nutrition. ${ }^{276}$ The main applications of nanoclays are summarized in Table 4.

Table 4 Applications of nanoclays.

\begin{tabular}{|l|l|}
\hline Nanoclays & Functions \\
\hline Halloysite & $\begin{array}{l}\text { Anticorrosion effect. } \\
\text { Bone implants. }\end{array}$ \\
\hline $\begin{array}{l}\text { Halloysite } \\
\text { Smectites }\end{array}$ & $\begin{array}{l}\text { Remediation by adsorption of inorganic and organic } \\
\text { pollutants (dyes, heavy metals, pesticides, volatile organic } \\
\text { compounds). } \\
\text { Drug delivery: ibuprofen, donepezil. }\end{array}$ \\
\hline
\end{tabular}




\begin{tabular}{|l|l|}
\hline Smectites & $\begin{array}{l}\text { Animal nutrition. Fillers for polymers. Excipients and active } \\
\text { agents. }\end{array}$ \\
\hline Laponite & $\begin{array}{l}\text { Osteogenic induction of responsive cells. Thickeners in } \\
\text { dentifrices for hypersensitive teeth. Cosmetic compositions. } \\
\text { Lightweight rubber. Absorbent for sequestering skin } \\
\text { irritants. Oxygen gas barriers. }\end{array}$ \\
\hline
\end{tabular}

\section{Conclusions}

In summary, advances have been made in the synthesis of porous nanosized materials (zeolites and clays). The developments in the synthesis and post-synthesis modification of the nanosized microporous materials resulted in 19 nanosized zeolites, 5 zeolites prepared in the form of nanosheets and 5 nanoclays with variable physicochemical properties. At present we dispose with relatively large set of materials with different characteristics useful for various applications.

Substantial progress has been made in the nanosized zeolite processing using template free precursor suspensions resulting in highly crystalline materials with yield comparable to commercial micronsized zeolites. Circumventing the use of an organic template is important step ahead in the future extensive application of nanosized zeolites. The zeolite can be used without applying high temperature calcination that is commonly related with this undesired aggregation and even partial amorphization of crystalline nanoparticles. Thus all advantages of suspensions containing discrete zeolite nanocrystals can be explored as well.

At present the available nanosized zeolites offer tuneable crystals size and chemical composition, diverse morphology, large external surface area, fast diffusion, high stability in suspensions, and no toxicity, which will result in enlargement of their applications. These properties are nicely complemented by the nanoclays that exhibit high swelling in contact with water and polar solvents, ability to adsorbed large molecules, and also they have high external and internal specific surface area and flexible rheological behaviour.

The unique properties of the nanosized zeolites and nanoclays in free or fixed forms make them ideal candidates for nanotechnology applications, where in addition to the nanosized dimensions, particles with high surface area, variable hydrohilicity/hydrophobicity, easy shaping, and high thermal and colloidal stabilities are required. Consequently, the applications of nanosized porous crystals range from polymer and toothpaste fillers to medical contrast carriers and active part of high technological sensing devices. The list of application is much 
longer as can be seen in the previous sections and continues growing. Most of these applications require customized nanosized materials. Hence, we believe that future efforts will be oriented to better control of the properties and more efficient production of nanosized zeolites and nanoclays. Their processing to ultimate product will also be further optimized.

The nanosized zeolites and nanoclays will be more and more exposed to human via inhalation, skin or swallowing. Therefore information on the toxicity of nanosized zeolites and nanoclays prior further application is of great interests. The low cytotoxic activity of nanosized zeolites with different sizes, compositions and shapes were reported and this is expected to enlarge their future industrial and medical applications. Zeolite materials have been considered for medical use due to their stability in biological environments. Based on the advantages such as small size and controlled release, zeolites and clays modified with targeting molecules are recognized for application in controlled drug treatments. Additionally nanosized zeolites are also investigated as magnetic resonance imaging agents, and enzymeimmobilizing carriers. The multifunctional capabilities of zeolites extend applications to fluorescent imaging and heat therapy. Nanosized zeolites have been studied as dietary supplements, antimicrobial agents, or adjuvants in anticancer therapy. They are expected to play an ever-increasing role in in new products in medical, food and cosmetic industries.

Similarly to zeolites the nanoclays are used for adsorption of inorganic and organic pollutants (dyes, heavy metals, pesticides, volatile organic compounds), for drug deliver and bone implants, as fillers for polymers and lightweight devices, anticorrosion layers and oxygen gas barrier.

Although the nanosized zeolites and nanoclays are used in similar fields, they are complementary in their used due to the specificity of their structures and related physicochemical properties. Therefore even larger "cooperation" between these two families of nanosized porous materials can be expected in the future.

\section{Acknowledgements}

The financial support from ZEOXY Emergence and the Lower-Normandy Region (France) is acknowledged. VV acknowledges the financial support from the MicroGreen project (ANR12-IS08-0001-01).

\section{References}

1 R. M. Barrer, Zeolites and clay minerals as sorbents and molecular sieves, London, 1978. 
2 R. W. Tschernich, Zeolites of the world, Phoenix, 1992.

3 R. M. Barrer, Hydrothermal chemistry of zeolites, Academic Press, London, 1982.

4 L. Tosheva and V. P. Valtchev, Chem. Mater., 2005, 17, 2494-2513.

5 S. Mintova, J.-P. Gilson and V. Valtchev, Nanoscale, 2013, 5, 6693-703.

6 V. Valtchev and L. Tosheva, Chem. Rev., 2013, 113, 6734-6760.

7 C. S. Cundy and P. A. Cox, Microporous Mesoporous Mater., 2005, 82, 1-78.

8 D. P. Serrano and R. van Grieken, J. Mater. Chem., 2001, 11, 2391-2407.

9 C. Madsen and C. J. H. Jacobsen, Chem. Commun., 1999, 673-674.

10 B. Wang, H. Z. Ma and Q. Z. Shi, Chinese Chem. Lett., 2002, 13, 385-391.

11 H. Wang, B. a. Holmberg and Y. Yan, J. Am. Chem. Soc., 2003, 125, 9928-9929.

12 D. P. Serrano, J. Aguado, J. M. Escola, J. M. Rodríguez and Á. Peral, Chem. Mater., 2006, 18, 2462-2464.

13 J. Aguado, D. P. Serrano and J. M. Rodríguez, Microporous Mesoporous Mater., 2008, 115, 504-513.

14 C. Jo, J. Jung, H. S. Shin, J. Kim and R. Ryoo, Angew. Chemie - Int. Ed., 2013, 52, 10014-10017.

15 A. K. Jamil, O. Muraza, M. Sanhoob, T. Tago, H. Konno, Y. Nakasaka and T. Masuda, J. Anal. Appl. Pyrolysis, 2014, 110, 338-345.

16 Z. Cheng, S. Han, W. Sun and Q. Qin, Mater. Lett., 2013, 95, 193-196.

17 G. A. Thompset, W. C. Conner and K. S. Yngvesson, ChemPhysChem, 2013, 7, 295304.

18 F. M. Shalmani, R. Halladj and S. Askari, Powder Technol., 2012, 221, 395-402.

19 S. Askari, S. Miar Alipour, R. Halladj and M. H. Davood Abadi Farahani, J. Porous Mater., 2012, 20, 285-302.

20 P. Pal, J. K. Das, N. Das and S. Bandyopadhyay, Ultrason. Sonochem., 2013, 20, 314 321.

21 M. B. Yue, N. Yang, W. Q. Jiao, Y. M. Wang and M. Y. He, Solid State Sci., 2013, 20, $1-7$.

22 X. Meng, Y. Zhang, M. Meng and W. Pang, in Proceedings 9th Int. Zeolite Conference, eds. R. von Ballmoos, J. B. Higgins and M. M. J. Treacy, ButterworthHeinemann, Stoneham, MA, 1993, pp. 297-304.

23 B. . Schoeman, J. Sterte and J.-E. Otterstedt, Zeolites, 1994, 14, 110-116.

24 B. J. Schoeman, J. Sterte and J.-E. Otterstedt, Zeolites, 1994, 14, 208-216. 
B. J. Schoeman, J. Sterte and J.-E. Otterstedt, J. Colloid Interface Sci., 1995, 170, 449456.

26 A. E. Persson, B. J. Schoeman, J. Sterte and J.-E. Otterstedt, Zeolites, 1994, 14, 557567.

27 B. J. Schoeman and O. Regev, Zeolites, 1996, 17, 447-456.

28 J. N. Watson, A. S. Brown, L. E. Iton and J. W. White, J. Chem. Soc. Faraday Trans., 1998, 94, 2181-2186.

29 N. D. Hould and R. F. Lobo, Chem. Mater., 2008, 20, 5807-5815.

30 T. M. Davis, T. O. Drews, H. Ramanan, C. He, J. Dong, H. Schnablegger, M. a Katsoulakis, E. Kokkoli, A. V McCormick, R. L. Penn and M. Tsapatsis, Nat. Mater., 2006, 5, 400-408.

31 S. Kumar, Z. Wang, R. Lee Perm and M. Tsapatsis, J. Am. Chem. Soc., 2008, 130, 17284-17286.

32 C. E. A. Kirschhock, V. Buschmann, S. Kremer, R. Ravishankar, C. J. Y. Houssin, B. L. Mojet, R. A. Van Santen, P. J. Grobet, P. A. Jacobs and J. A. Martens, Angew. Chemie - Int. Ed., 2001, 40, 2637-2640.

33 C. E. A. Kirschhock, S. P. B. Kremer, J. Vermant, G. Van Tendeloo, P. A. Jacobs and J. A. Martens, Chem. - A Eur. J., 2005, 11, 4306-4313.

34 S. Mintova, N. H. Olson, V. Valtchev and T. Bein, Science (80-. )., 1999, 283, 958960.

35 S. Mintova, N. Olson and T. Bein, Angew. Chem. Int. Ed. Engl., 1999, 38, 3201-3204.

36 E.-P. Ng, D. Chateigner, T. Bein, V. Valtchev and S. Mintova, Science (80-. )., 2012, $335,70-73$.

37 E.-P. Ng, J.-M. Goupil, A. Vicente, C. Fernandez, R. Retoux, V. Valtchev and S. Mintova, Chem. Mater., 2012, 24, 4758-4765.

38 Eur. Pat., 364352, 1990.

39 G. Lischke, E. Schreier, B. Parlitz, I. Pitsch, U. Lohse and M. Woettke, Appl. Catal. A Gen., 1995, 129, 57-67.

40 V. Georgieva, A. Vicente, C. Fernandez, R. Retoux, A. Palcic, V. Valtchev and S. Mintova, Cryst. Growth Des., 2015, 150225102729005.

41 H. Awala, J.-P. Gilson, R. Retoux, P. Boullay, J.-M. Goupil, V. Valtchev and S. Mintova, Nat. Mater., 2015.

42 A. Corma, V. Fornes, S. B. Pergher, T. L. M. Maesen and J. G. Buglass, 1998, 396, $353-356$. 
43 A. Corma, U. Diaz, M. Domine and V. Fornés, Angew. Chem. Int. Ed. Engl., 2000, 39, $1499-1501$.

44 A. Corma, V. Fornés and U. Díaz, Chem. Commun., 2001, 2642-2643.

45 M. Choi, K. Na, J. Kim, Y. Sakamoto, O. Terasaki and R. Ryoo, Nature, 2009, 461, 246-249.

46 K. Na, W. Park, Y. Seo and R. Ryoo, Chem. Mater., 2011, 23, 1273-1279.

47 X. Zhang, D. Liu, D. Xu, S. Asahina, K. a. Cychosz, K. V. Agrawal, Y. Al Wahedi, a. Bhan, S. Al Hashimi, O. Terasaki, M. Thommes and M. Tsapatsis, Science (80-. )., 2012, 336, 1684-1687.

48 W. Fan, M. a Snyder, S. Kumar, P.-S. Lee, W. C. Yoo, A. V McCormick, R. Lee Penn, A. Stein and M. Tsapatsis, Nat. Mater., 2008, 7, 984-991.

49 W. C. Yoo, S. Kumar, Z. Wang, N. S. Ergang, W. Fan, G. N. Karanikolos, A. V. McCormick, R. L. Penn, M. Tsapatsis and A. Stein, Angew. Chemie - Int. Ed., 2008, 47, 9096-9099.

50 Z. Wang, P. Dornath, C. C. Chang, H. Chen and W. Fan, Microporous Mesoporous Mater., 2013, 181, 8-16.

51 R. Kore, R. Srivastava and B. Satpati, Chem. - A Eur. J., 2014, 20, 11511-11521.

52 Q. Zhang, H. Yang and W. Yan, RSC Adv., 2014, 4, 56938-56944.

53 S. Lin, L. Shi and T. Yu, J. Phys. Chem. C, 2015, 119, 1008-1015.

54 D. Xu, Z. Jing, F. Cao, H. Sun and S. Che, Chem. Mater., 2014, 26, 4612-4619.

55 Y. Seo, K. Cho, Y. Jung and R. Ryoo, ACS Catal., 2013, 3, 713-720.

56 S. Hu, J. Shan, Q. Zhang, Y. Wang, Y. Liu, Y. Gong, Z. Wu and T. Dou, Appl. Catal. A Gen., 2012, 445-446, 215-220.

57 H. W. Lee, S. H. Park, J.-K. Jeon, R. Ryoo, W. Kim, D. J. Suh and Y.-K. Park, Catal. Today, 2014, 232, 119-126.

58 H. Y. Luo, L. Bui, W. R. Gunther, E. Min and Y. Román-Leshkov, ACS Catal., 2012, 2, 2695-2699.

59 K. Na, M. Choi and R. Ryoo, Microporous Mesoporous Mater., 2013, 166, 3-19.

60 K. Möller and T. Bein, Chem. Soc. Rev., 2013, 42, 3689-3707.

61 F. Bergaya and G. Lagaly, In Clay-Based Polymer, Nanocomposites, Chantilly, VA, 1997.

62 A. Doménech, M. T. Doménech-Carbó, M. Sánchez del Río, M. L. Vázquez de Agredos Pascual and E. Lima, New J. Chem., 2009, 33, 2371-2379. 
63 B. Hubbard, W. Kuang, A. Moser, G. A. Facey and C. Detellier, Clays Clay Miner., 2003, 51, 318-326.

64 M. Jose-Yacaman, L. Rendon, J. Arenas and M. C. Serra Puche, Science (80-. )., 1996, 273, 223-225.

H. Van Olphen, Science, 1966, 154, 645-646.

66 J. F. L. F. Bergaya, M. Jaber, in Rubber-Clay Nanocomposites: Science, Technology, and Applications, ed. Maurizio Galimberti, John Wiley \& Sons, Inc, 2011, pp. 3-44.

67 M. Jaber, S. Komarneni and C.-H. Zhou, Handbook of Clay Science, Elsevier, 2013, vol. 5 .

68 L. Ammann, F. Bergaya and G. Lagaly, Clay Miner., 2005, 40, 441-453.

69 G. E. Christidis, A. E. Blum and D. D. Eberl, Appl. Clay Sci., 2006, 34, 125-138.

70 K. Norrish, Discuss. Faraday Soc., 1954, 18, 120-134.

71 R. W. Mooney, A. G. Keenan and L. A. Wood, J. Am. Chem. Soc., 1952, 74, 13711374.

72 L. G. and J. J. F. F. Annabi-Bergaya, M. I. Cruz, Mineral. Soc., 1979, 249-258.

73 L. J. Michot and F. Villiéras, Handbook of Clay Science, Elsevier, 2006, vol. 1.

74 L. Bailey, H. N. W. Lekkerkerker and G. C. Maitland, Soft Matter, 2015, 11, 222-236.

75 J. H. Rayner, in Colloques Internationaux du CNRS, Genèse et Synthèse des Argiles, 1962, pp. 124-127.

76 A. Decarreau, Bull. Minéralogie, 1980, 103, 579-590.

77 A. Decarreau, S. Petit, P. Vieillard and N. Dabert, Eur. J. Mineral., 2004, 16, 85-90.

78 F. J. Huertas, J. Cuadros, F. Huertas and J. Linares, Am. J. Sci., 2000, 300, 504-527.

79 J. T. Kloprogge, S. Komarneni and J. E. Amonette, Clays Clay Miner., 1999, 47, 529554.

80 V. C. Farmer, A. R. Fraser and J. M. Tait, J. Chem. Soc. Chem. Commun., 1977, 462463.

81 S. Mukherjee, V. M. Bartlow and S. Nair, Chem. Mater., 2005, 17, 4900-4909.

82 US pat., 4098676 A, 1978.

83 F. Kooli, Y. Z. Khimyak, S. F. Alshahateet and F. Chen, Langmuir, 2005, 21, 87178723.

84 C. Lam, K. Lau, H. Cheung and H. Ling, Mater. Lett., 2005, 59, 1369-1372.

85 L. A. Pérez-Maqueda, F. Franco and J. L. Pérez-Rodríguez, J. Eur. Ceram. Soc., 2005, 25, 1463-1470.

86 M. Daneshvar and E. Gulari, J. Supercrit. Fluids, 1992, 5, 143-150. 
US pat., 7055566 B2, 2006.

88 E. C. Bate-Smith, Nature, 1965, 206, 538-539.

89 C. B. Agbugba, B. A. Hendriksen, B. Z. Chowdhry and M. J. Snowden, Colloids Surfaces A Physicochem. Eng. Asp., 1998, 137, 155-164.

90 M. Birgersson, O. Karnland and U. Nilsson, Phys. Chem. Earth, Parts A/B/C, 2008, 33, S527-S530.

91 D. M. Anderson and A. R. Tice, Soil Sci. Soc. Am. J., 1971, 35, 47-54.

92 D. F. Eckel, M. P. Balogh, P. D. Fasulo and W. R. Rodgers, J. Appl. Polym. Sci., 2004, 93, 1110-1117.

93 A. Bafna, G. Beaucage, F. Mirabella and S. Mehta, Polymer (Guildf)., 2003, 44, $1103-$ 1115.

94 S. I. Marras, I. Zuburtikudis and C. Panayiotou, Eur. Polym. J., 2007, 43, 2191-2206.

95 H.-M. Park, X. Li, C.-Z. Jin, C.-Y. Park, W.-J. Cho and C.-S. Ha, Macromol. Mater. Eng., 2002, 287, 553-558.

96 E. Balnois, S. Durand-Vidal and P. Levitz, Langmuir, 2003, 19, 6633-6637.

97 R. S. Alvim and C. R. Miranda, Phys. Chem. Chem. Phys., 2015, 17, 4952-4960.

98 S. Aoyama, Y. T. Park, C. W. Macosko, T. Ougizawa and G. Haugstad, Langmuir, 2014, 30, 12950-12959.

99 Z. Wang, H. Wang, A. Mitra, L. Huang and Y. Yan, Adv. Mater., 2001, 13, 746-749.

100 Z. B. Wang, A. Mitra, H. T. Wang, L. M. Huang and Y. Yan, Adv. Mater., 2001, 13, $1463-1466$.

101 A. Mitra, L. Huang and S. Li, Ind. Eng. Chem. Res., 2004, 43, 2946-2949.

102 C.-H. Chen, S.-Y. Li, A. S. T. Chiang, A. T. Wu and Y. S. Sun, Sol. Energy Mater. Sol. Cells, 2011, 95, 1694-1700.

103 C. M. Lew, R. Cai and Y. Yan, Acc. Chem. Res., 2010, 43, 210-219.

104 C.-S. Wu, J.-Y. Liao, S.-Y. Fang and A. S. T. Chiang, Adsorption, 2009, 16, 69-74.

105 X. Xu, J. Wang and Y. Long, Sensors, 2006, 6, 1751-1764.

106 K. Sahner, G. Hagen, D. Schönauer, S. Reiß and R. Moos, Solid State Ionics, 2008, 179, 2416-2423.

107 Y. Zheng, X. Li and P. K. Dutta, Sensors, 2012, 12, 5170-5194.

108 http://www.grandviewresearch.com/industry-analysis/gas-sensors-market, 2014.

109 S. Mandal, H. L. Williams and H. K. Hunt, Microporous Mesoporous Mater., 2015, 203, 245-258.

110 D. Banerjee, Z. Hu and J. Li, Dalton Trans., 2014, 43, 10668-10685. 
111 T. Bein and S. Mintova, Zeolites and Ordered Mesoporous Materials: Progress and Prospects, Elsevier, 2005, vol. 157.

112 M. Zaarour, B. Dong, I. Naydenova, R. Retoux and S. Mintova, Microporous Mesoporous Mater., 2014, 189, 11-21.

113 K. Sahner and R. Moos, Sens. Lett., 2008, 6, 808-811.

114 P. Payra and P. K. Dutta, Microporous Mesoporous Mater., 2003, 64, 109-118.

115 T. A. Ruda-Eberenz, A. Nagy, W. J. Waldman and P. K. Dutta, Langmuir, 2008, 24, 9140-9147.

116 J.-C. Yang, J. V. Spirig, D. Karweik, J. L. Routbort, D. Singh and P. K. Dutta, Sensors Actuators B Chem., 2008, 131, 448-454.

117 R. Binions, A. Afonja, S. Dungey, D. W. Lewis, I. P. Parkin and D. E. Williams, IEEE Sens. J., 2011, 11, 1145-1151.

118 D. C. Pugh, E. J. Newton, a. J. T. Naik, S. M. V. Hailes and I. P. Parkin, J. Mater. Chem. A, 2014, 2, 4758-4764.

119 J.-C. Yang and P. K. Dutta, J. Phys. Chem. C, 2007, 111, 8307-8313.

120 R. Binions, H. Davies, A. Afonja, S. Dungey, D. Lewis, D. Williams and I. Parkin, J. Electrochem. Soc., 2009, 156, J46 - J51.

121 N. Densakulprasert, L. Wannatong, D. Chotpattananont, P. Hiamtup, A. Sirivat and J. Schwank, Mater. Sci. Eng. B, 2005, 117, 276-282.

122 P. Chanthaanont and A. Sirivat, e-Polymers, 2012, 12, 106-116.

123 S. Thomas, P. Bazin, L. Lakiss, V. De Waele and S. Mintova, Langmuir, 2011, 27, $14689-14695$.

124 L. Lakiss, S. Thomas, P. Bazin, V. de Waele and S. Mintova, Microporous Mesoporous Mater., 2014, 200, 326-333.

125 I. G. Giannakopoulos, D. Kouzoudis, C. A. Grimes and V. Nikolakis, Adv. Funct. Mater., 2005, 15, 1165-1170.

126 F. L. Dickert, P. Achatz and K. Halikias, Fresenius. J. Anal. Chem., 2001, 371, 11-15.

127 M. Vilaseca, J. Coronas, A. Cirera, A. Cornet, J. R. Morante and J. Santamaría, Catal. Today, 2003, 82, 179-185.

128 D. Jadsadapattarakul, C. Thanachayanont, J. Nukeaw and T. Sooknoi, Sensors Actuators B Chem., 2010, 144, 73-80.

129 L. Wannatong and A. Sirivat, React. Funct. Polym., 2008, 68, 1646-1651.

130 T. Baimpos, L. Gora, V. Nikolakis and D. Kouzoudis, Sensors Actuators A Phys., 2012, 186, 21-31. 
131 S. Reiß, G. Hagen and R. Moos, Sensors, 2008, 8, 7904-7916.

132 A. Zampieri, A. Dubbe, W. Schwieger, A. Avhale and R. Moos, Microporous Mesoporous Mater., 2008, 111, 530-535.

133 G. Hagen and R. Moos, Sens. Lett., 2011, 9, 110-113.

134 J. Zhang, X. Tang, J. Dong, T. Wei and H. Xiao, Sensors Actuators B Chem., 2009, 135, 420-425.

135 M. E. Franke, U. Simon, R. Moos, A. Knezevic, R. Mueller and C. Plog, Phys. Chem. Chem. Phys., 2003, 5, 5195-5198.

136 S. Konkayan, P. Chanthaanont, W. Prissanaroon, P. Hormnirun and A. Sirivat, Mater. Sci. Technol., 2013, 28, 332-338.

137 Y. Zheng, M. R. Mullen, J. Wang and P. K. Dutta, Sensors Actuators B Chem., 2014, 193, 542-551.

138 A. Satsuma, D. Yang and K. Shimizu, Microporous Mesoporous Mater., 2011, 141, $20-25$.

139 U. Simon and M. . Franke, Microporous Mesoporous Mater., 2000, 41, 1-36.

140 A. Dubbe, Solid State Ionics, 2008, 179, 1645-1647.

141 S. P. Mondal, P. K. Dutta, G. W. Hunter, B. J. Ward, D. Laskowski and R. A. Dweik, Sensors Actuators B Chem., 2011, 158, 292-298.

142 T. Yu, Y. Zhang, C. You, J. Zhuang, B. Wang, B. Liu, Y. Kang and Y. Tang, Chem. A Eur. J., 2006, 12, 1137-1143.

143 W. Shan, T. Yu, B. Wang, J. Hu, Y. Zhang, X. Wang and Y. Tang, Chem. Mater., 2006, 18, 3169-3172.

144 L. Lin and J. T. Guthrie, J. Memb. Sci., 2006, 278, 173-180.

145 D. Bergé-Lefranc, C. Vagner, R. Calaf, H. Pizzala, R. Denoyel, P. Brunet, H. Ghobarkar and O. Schäf, Microporous Mesoporous Mater., 2012, 153, 288-293.

146 L. Narasimhan, P. Boulet, B. Kuchta, C. Vagner, O. Schäf and R. Denoyel, Appl. Surf. Sci., 2010, 256, 5470-5474.

147 V. Wernert, O. Schäf, V. Faure, P. Brunet, L. Dou, Y. Berland, P. Boulet, B. Kuchta and R. Denoyel, J. Biotechnol., 2006, 123, 164-173.

148 V. Wernert, O. Schäf, H. Ghobarkar and R. Denoyel, Microporous Mesoporous Mater., 2005, 83, 101-113.

149 G. Lesaffer, Nephrol. Dial. Transplant., 2000, 15, 50-57.

150 P. Brunet, L. Dou, C. Cerini and Y. Berland, Adv. Ren. Replace. Ther., 2003, 10, 310 320. 
151 X. Li and P. K. Dutta, J. Phys. Chem. C, 2010, 114, 7986-7994.

152 B. V. Lotsch, C. B. Knobbe and G. a. Ozin, Small, 2009, 5, 1498-1503.

153 K. Lazarova, H. Awala, S. Thomas, M. Vasileva, S. Mintova and T. Babeva, Sensors, 2014, 14, 12207-12218.

154 T. Babeva, H. Awala, M. Vasileva, J. El Fallah, K. Lazarova, S. Thomas and S. Mintova, Dalton Trans., 2014, 43, 8868-8876.

155 L. D. Bonifacio, B. V. Lotsch, D. P. Puzzo, F. Scotognella and G. A. Ozin, Adv. Mater., 2009, 21, 1641-1646.

156 J. Kobler, B. V. Lotsch, G. a. Ozin and T. Bein, ACS Nano, 2009, 3, 1669-1676.

157 B. V Lotsch, F. Scotognella, K. Moeller, T. Bein and G. a Ozin, Proc. SPIE - Int. Soc. Opt. Eng., 2010, 7713, 77130V-77130V-10.

158 T. Babeva, R. Todorov, B. Gospodinov, N. Malinowski, J. El Fallah and S. Mintova, J. Mater. Chem., 2012, 22, 18136-18138.

159 B. Liu, F. Yan, J. Kong and J. Deng, Anal. Chim. Acta, 1999, 386, 31-39.

160 A. P. Turner, Science, 2000, 290, 1315-1317.

161 H. Huang, J. Zhou, S. Chen, L. Zeng and Y. Huang, Sensors Actuators B Chem., 2004, 101, 316-321.

162 D. Cody, E. Mihaylova, L. O’Neill, T. Babeva, H. Awala, R. Retoux, S. Mintova and I. Naydenova, Opt. Mater. (Amst)., 2014, 37, 181-187.

163 M. Moothanchery, I. Naydenova, S. Mintova and V. Toal, Opt. Express, 2011, 19, 25786-25791.

164 E. Leite, I. Naydenova, S. Mintova, L. Leclercq and V. Toal, Appl. Opt., 2010, 49, $3652-3660$.

165 E. Leite, T. Babeva, E. P. Ng, V. Toal, S. Mintova and I. Naydenova, J. Phys. Chem. C, 2010, 114, 16767-16775.

166 G. Calzaferri, S. Huber, H. Maas and C. Minkowski, Angew. Chemie - Int. Ed., 2003, 42, 3732-3758.

167 V. Vohra, A. Bolognesi, G. Calzaferri and C. Botta, Langmuir, 2009, 25, 1201912023.

168 P. Atienzar, S. Valencia, A. Corma and H. García, ChemPhysChem, 2007, 8, 11151119.

169 H. S. Kim, N. C. Jeong and K. B. Yoon, Langmuir, 2011, 27, 14678-14688.

170 US pat., 20100119736 A1, 2010.

171 S. E. Lehman and S. C. Larsen, Environ. Sci. Nano, 2014, 1, 200-213. 
172 R. S. Bedi, D. E. Beving, L. P. Zanello and Y. Yan, Acta Biomater., 2009, 5, 32653271.

173 L. C. J. Thomassen, D. Napierska, D. Dinsdale, N. Lievens, J. Jammaer, D. Lison, C. E. A. Kirschhock, P. H. Hoet and J. A. Martens, Nanotoxicology, 2012, 6, 472-485.

174 A. Petushkov, J. Intra, J. B. Graham, S. C. Larsen and A. K. Salem, Chem. Res. Toxicol., 2009, 22, 1359-1368.

175 Z. Li, J. Hüve, C. Krampe, G. Luppi, M. Tsotsalas, J. Klingauf, L. De Cola and K. Riehemann, Small, 2013, 9, 1809-1820.

176 H. Zhang, D. R. Dunphy, X. Jiang, H. Meng, B. Sun, D. Tarn, M. Xue, X. Wang, S. Lin, Z. Ji, R. Li, F. L. Garcia, J. Yang, M. L. Kirk, T. Xia, J. I. Zink, A. Nel and C. J. Brinker, J. Am. Chem. Soc., 2012, 134, 15790-15804.

177 T. Kihara, Y. Zhang, Y. Hu, Q. Mao, Y. Tang and J. Miyake, J. Biosci. Bioeng., 2011, 111, 725-730.

178 R. Mellaerts, J. Delvaux, P. Levêque, B. Wuyts, G. Van den Mooter, P. Augustijns, B. Gallez, I. Hermans and J. Martens, RSC Adv., 2013, 3, 900-909.

179 K. Bhattacharya, P. C. Naha, I. Naydenova, S. Mintova and H. J. Byrne, Toxicol. Lett., 2012, 215, 151-160.

180 S. Laurent, E.-P. Ng, C. Thirifays, L. Lakiss, G.-M. Goupil, S. Mintova, C. Burtea, E. Oveisi, C. Hébert, M. de Vries, M. M. Motazacker, F. Rezaee and M. Mahmoudi, Toxicol. Res. (Camb)., 2013, 2, 270-279.

181 N. Tirtaatmadja, G. Mortimer, E.-P. Ng, H. A. Ahmad, S. Mintova, V. Serpooshan, R. F. Minchin and M. Mahmoudi, J. Iran. Chem. Soc., 2014, 12, 317-323.

182 D. D. Kavak and S. Ülkü, J. Porous Mater., 2012, 20, 331-338.

183 C. A. Strassert, M. Otter, R. Q. Albuquerque, A. Hone, Y. Vida, B. Maier and L. De Cola, Angew. Chemie - Int. Ed., 2009, 48, 7928-7931.

184 D. Campoccia, L. Montanaro and C. R. Arciola, Biomaterials, 2013, 34, 8533-8554.

185 L. Rizzello and P. P. Pompa, Chem. Soc. Rev., 2014, 43, 1501-1518.

186 Z. M. Xiu, Q. B. Zhang, H. L. Puppala, V. L. Colvin and P. J. J. Alvarez, Nano Lett., 2012, 12, 4271-4275.

187 L. Tosheva, A. Brockbank, B. Mihailova, J. Sutula, J. Ludwig, H. Potgieter and J. Verran, J. Mater. Chem., 2012, 22, 16897-16905.

188 Y. Inoue, J. Biomater. Nanobiotechnol., 2012, 03, 114-117.

189 P. Saint-Cricq, Y. Kamimura, K. Itabashi, A. Sugawara-Narutaki, A. Shimojima and T. Okubo, Eur. J. Inorg. Chem., 2012, 2012, 3398-3402. 
190 L. Ferreira, A. M. Fonseca, G. Botelho, C. A.- Aguiar and I. C. Neves, Microporous Mesoporous Mater., 2012, 160, 126-132.

191 B. Dong, S. Belkhair, M. Zaarour, L. Fisher, J. Verran, L. Tosheva, R. Retoux, J.-P. Gilson and S. Mintova, Nanoscale, 2014, 6, 10859-10864.

192 C. Chiericatti, J. C. Basílico, M. L. Z. Basílico and J. M. Zamaro, Microporous Mesoporous Mater., 2014, 188, 118-125.

193 T. Møretrø, G. S. Høiby-Pettersen, C. K. Halvorsen and S. Langsrud, Food Control, 2012, 28, 118-121.

194 S. Sabbani, D. Gallego-Perez, A. Nagy, W. James Waldman, D. Hansford and P. K. Dutta, Microporous Mesoporous Mater., 2010, 135, 131-136.

195 S. Fox, T. S. Wilkinson, P. S. Wheatley, B. Xiao, R. E. Morris, A. Sutherland, a. J. Simpson, P. G. Barlow, A. R. Butler, I. L. Megson and A. G. Rossi, Acta Biomater., 2010, 6, 1515-1521.

196 A. Bertucci, H. Lülf, D. Septiadi, A. Manicardi and R. Corradini, Adv. Healthc. Mater., 2014, 3, 1812-1817.

197 É. Csajbók, I. Bányai, L. Vander Elst, R. N. Muller, W. Zhou and J. a. Peters, Chem. A Eur. J., 2005, 11, 4799-4807.

198 M. M. Tsotsalas, K. Kopka, G. Luppi, S. Wagner, M. P. Law, M. Schäfers and L. De Cola, ACS Nano, 2010, 4, 342-348.

199 N. Ndiege, R. Raidoo, M. K. Schultz and S. Larsen, Langmuir, 2011, 27, 2904-2909.

200 H. Zhang, Y. Kim and P. K. Dutta, Microporous Mesoporous Mater., 2006, 88, 312318.

201 I. Braschi, G. Gatti, G. Paul, C. E. Gessa, M. Cossi and L. Marchese, Langmuir, 2010, 26, 9524-9532.

202 I. Braschi, S. Blasioli, L. Gigli, C. E. Gessa, A. Alberti and A. Martucci, J. Hazard. Mater., 2010, 178, 218-225.

203 A. Martucci, L. Pasti, N. Marchetti, A. Cavazzini, F. Dondi and A. Alberti, Microporous Mesoporous Mater., 2012, 148, 174-183.

204 N. Vilaça, R. Amorim, O. Martinho, R. M. Reis, F. Baltazar, A. M. Fonseca and I. C. Neves, J. Mater. Sci., 2011, 46, 7511-7516.

205 Z. Popović, M. Otter, G. Calzaferri and L. De Cola, Angew. Chemie - Int. Ed., 2007, 46, 6188-6191.

206 Y. Zhang, Y. Liu, J. Kong, P. Yang, Y. Tang and B. Liu, Small, 2006, 2, 1170-1173.

207 M. E. Davis, Nature, 2002, 417, 813-821. 
208 T. Farías, A. R. Ruiz-Salvador and A. Rivera, Microporous Mesoporous Mater., 2003, 61, 117-125.

209 A. Kulak, S. R. Hall and S. Mann, Chem. Commun. (Camb)., 2004, 576-577.

210 T. Ukmar, T. Čendak, M. Mazaj, V. Kaučič and G. Mali, J. Phys. Chem. C, 2012, 116, 2662-2671.

211 P. Horcajada, A. Rámila, G. Férey and M. Vallet-Regí, Solid State Sci., 2006, 8, $1243-$ 1249.

212 P. Horcajada, C. Márquez-Alvarez, A. Rámila, J. Pérez-Pariente and M. Vallet-Regí, Solid State Sci., 2006, 8, 1459-1465.

213 M. G. Rimoli, M. R. Rabaioli, D. Melisi, A. Curcio, S. Mondello, R. Mirabelli and E. Abignente, J. Biomed. Mater. Res. - Part A, 2008, 87, 156-164.

214 S. Grund, T. Doussineau, D. Fischer and G. J. Mohr, J. Colloid Interface Sci., 2012, $365,33-40$.

215 A. Datt, D. Fields and S. C. Larsen, J. Phys. Chem. C, 2012, 116, 21382-21390.

216 A. Datt, E. A. Burns, N. A. Dhuna and S. C. Larsen, Microporous Mesoporous Mater., 2013, 167, 182-187.

217 N. Vilaça, R. Amorim, A. F. Machado, P. Parpot, M. F. R. Pereira, M. Sardo, J. Rocha, A. M. Fonseca, I. C. Neves and F. Baltazar, Colloids Surfaces B Biointerfaces, 2013, 112, 237-244.

218 R. Amorim, N. Vilaça, O. Martinho, R. M. Reis, M. Sardo, J. Rocha, A. M. Fonseca, F. Baltazar and I. C. Neves, J. Phys. Chem. C, 2012, 116, 25642-25650.

219 S. Ferdov, E. Shikova, Z. Ivanova, L. T. Dimowa, R. P. Nikolova, Z. Lin and B. L. Shivachev, RSC Adv., 2013, 3, 8843-8848.

220 Q. Tang, Y. Xu, D. Wu and Y. Sun, J. Solid State Chem., 2006, 179, 1513-1520.

221 A. Tavolaro, I. I. Riccio and P. Tavolaro, Microporous Mesoporous Mater., 2013, 167, $62-70$.

222 A. C. Nechifor, A. Ivan, S. I. Voicu, V. Danciulescu and R. Trusca, in Key Engineering Materials, 2014, vol. 583, pp. 91-94.

223 M. Vallet-Regí, F. Balas and D. Arcos, Angew. Chemie - Int. Ed., 2007, 46, 75487558.

224 I. I. Slowing, J. L. Vivero-Escoto, C.-W. Wu and V. S.-Y. Lin, Adv. Drug Deliv. Rev., 2008, 60, 1278-1288.

225 N. Ninan, Y. Grohens, A. Elain, N. Kalarikkal and S. Thomas, Eur. Polym. J., 2013, 49, 2433-2445. 
226 R. S. Bedi, G. Chow, J. Wang, L. Zanello and Y. S. Yan, Adv. Eng. Mater., 2012, 14, 200-206.

227 M. Danilczuk, K. Długopolska, T. Ruman and D. Pogocki, Mini Rev. Med. Chem., 2008, 8, 1407-1417.

228 S. a Osseni, S. Lechevallier, M. Verelst, P. Perriat, J. Dexpert-Ghys, D. Neumeyer, R. Garcia, F. Mayer, K. Djanashvili, J. a Peters, E. Magdeleine, H. Gros-Dagnac, P. Celsis and R. Mauricot, Nanoscale, 2014, 6, 555-564.

229 J. A. Peters and K. Djanashvili, Eur. J. Inorg. Chem., 2012, 2012, 1961-1974.

230 F. Lerouge, O. Melnyk, J.-O. Durand, L. Raehm, P. Berthault, G. Huber, H. Desvaux, A. Constantinesco, P. Choquet, J. Detour and M. Smaïhi, J. Mater. Chem., 2009, 19, $379-386$.

231 H.-L. Hsu, R. Selvin, J.-W. Cao, L. S. Roselin and M. Bououdina, Sci. Adv. Mater., 2011, 3, 939-943.

232 C. H. Fan, C. Y. Ting, H. J. Lin, C. H. Wang, H. L. Liu, T. C. Yen and C. K. Yeh, Biomaterials, 2013, 34, 3706-3715.

233 S. Mura, J. Nicolas and P. Couvreur, Nat. Mater., 2013, 12, 991-1003.

234 J. A. Litch and R. A. Bishop, Wilderness Environ. Med., 2000, 11, 189-191.

235 V. Rama Rao, S. Farooq and W. B. Krantz, AIChE J., 2010, 56, 354-370.

236 D. G. Seifu, T. T. Isimjan and K. Mequanint, Acta Biomater., 2011, 7, 3670-3678.

237 K. Bogunia-Kubik and M. Sugisaka, Biosystems, 2002, 65, 123-138.

238 P. S. Wheatley, A. R. Butler, M. S. Crane, S. Fox, B. Xiao, A. G. Rossi, I. L. Megson and R. E. Morris, J. Am. Chem. Soc., 2006, 128, 502-509.

239 M. Mowbray, X. Tan, P. S. Wheatley, A. G. Rossi, R. E. Morris and R. B. Weller, J. Invest. Dermatol., 2008, 128, 352-360.

240 US pat., 20090130154 A1, 2009.

241 Russ. Pat., 2151591 C1, 2004.

242 Int. pat., 8605389, 1986.

243 Eur. pat., 1172088 A3, 2003.

244 Int. pat., 9317661 (A1), 1993.

245 A. Diaconu, W. Russ, B. Klitzing and I. Ionel, J. Environ. Prot. Ecol., 2012, 13, 23312337.

246 A. Llorens, E. Lloret, P. A. Picouet, R. Trbojevich and A. Fernandez, Trends Food Sci. Technol., 2012, 24, 19-29.

247 E. P. Ng, L. Delmotte and S. Mintova, ChemSusChem, 2009, 2, 255-260. 
248 E.-P. $\mathrm{Ng}$ and S. Mintova, in Topics in Chemistry and Material Science: Advanced Micro- and Mesoporous Materials, ed. S. M. and G. V. K. Hadjiivanov, V. Valtchev, Coronet Books Incorporated, 2008, pp. 322-329.

249 K.-H. Tan, E.-P. Ng, H. Awala, R. R. Mukti, K.-L. Wong, S.-K. Yeong and S. Mintova, in Topics in Chemistry and Material Science: Advanced Micro- and Mesoporous Materials, eds. K. Hadjiivanov, V. Valtchev, S. Mintova and G. Vayssilov, 2014, pp. 102-108.

250 C. Viseras, P. Cerezo, R. Sanchez, I. Salcedo and C. Aguzzi, Appl. Clay Sci., 2010, 48, 291-295.

251 C. Aguzzi, P. Cerezo, C. Viseras and C. Caramella, Appl. Clay Sci., 2007, 36, 22-36.

252 Y. M. Lvov, D. G. Shchukin, H. Möhwald and R. R. Price, ACS Nano, 2008, 2, 814820.

253 N. G. Veerabadran, R. R. Price and Y. M. Lvov, Nano, 2007, 02, 115-120.

254 H. A. Patel, R. S. Somani, H. C. Bajaj and R. V. Jasra, Bull. Mater. Sci., 2006, 29, $133-145$.

255 M. T. Droy-Lefaix and F. Tateo, Handbook of Clay Science, Elsevier, 2006, vol. 1.

256 J. H.-Y. Chung, A. Simmons and L. A. Poole-Warren, Expert Opin. Drug Deliv., 2011, 8, 765-778.

257 J. I. Dawson and R. O. C. Oreffo, Adv. Mater., 2013, 25, 4069-4086.

258 Int. pat., $2002062310 \mathrm{~A} 1,2002$.

259 US pat., 6485733 B1, 2002.

260 S. M. Alhassan, S. Qutubuddin and D. a. Schiraldi, Langmuir, 2012, 28, 4009-4015.

261 J. Yoo, S. B. Lee, C. K. Lee, S. W. Hwang, C. Kim, T. Fujigaya, N. Nakashima and J. K. Shim, Nanoscale, 2014, 10824-10830.

262 D. C. Marcano, D. V. Kosynkin, J. M. Berlin, A. Sinitskii, Z. Sun, A. Slesarev, L. B. Alemany, W. Lu and J. M. Tour, ACS Nano, 2010, 4, 4806-4814.

263 D. G. Shchukin, S. V. Lamaka, K. A. Yasakau, M. L. Zheludkevich, M. G. S. Ferreira and H. Mohwald, J. Phys. Chem. C, 2008, 112, 958-964.

264 D. Rawtani and Y. K. Agrawal, Rev. Adv. Mater. Sci., 2012, 30, 282-295.

265 A. Okada and A. Usuki, Mater. Sci. Eng. C, 1995, 3, 109-115.

266 E. P. Giannelis, Adv. Mater., 1996, 8, 29-35.

267 P. LeBaron, Appl. Clay Sci., 1999, 15, 11-29.

268 M. Zanetti, S. Lomakin and G. Camino, Macromol. Mater. Eng., 2000, 279, 1-9.

269 R. A. Vaia, H. Ishii and E. P. Giannelis, Chem. Mater., 1993, 5, 1694-1696. 
270 I. A. Ramphal and M. E. Hagerman, Langmuir, 2015, 31, 1505-1515.

271 O. Eksik, J. Gao, S. A. Shojaee, A. Thomas, P. Chow, S. F. Bartolucci, D. a. Lucca and N. Koratkar, ACS Nano, 2014, 8, 5282-5289.

272 E. Kharlampieva, V. Kozlovskaya, B. Wallet, V. V. Shevchenko, R. R. Naik, R. Vaia, D. L. Kaplan and V. V. Tsukruk, ACS Nano, 2010, 4, 7053-7063.

273 T.-M. Wu and J.-Y. Wu, J. Macromol. Sci. Part B, 2007, 41, 17-31.

274 P. Das, J.-M. Malho, K. Rahimi, F. H. Schacher, B. Wang, D. E. Demco and A. Walther, Nat. Commun., 2015, 6, 5967.

275 Q. Wang, J. Zhang and A. Wang, Appl. Clay Sci., 2014, 87, 7-13.

276 Fr. pat., 2882997 (A1), 2006. 